\title{
EQUILÍBRIO E CICLOS
}

\section{Matheus Albergaria de Magalhães ${ }^{* *}$}

RESUMO A agenda de pesquisa relacionada a modelos de ciclos reais de negócios (Real-Business-Cycle models - RBC) apresentou um crescimento exponencial desde seu surgimento, no início da década de 1980. Os modelos iniciais do gênero partiam de economias simplificadas, sem imperfeições, buscando explicar as oscilações de curto prazo da economia (ciclos) a partir de um arcabouço de equilíbrio geral walrasiano. Atualmente, modelos RBC são amplamente usados na macroeconomia, com uma ênfase especial na análise dos aspectos quantitativos das flutuações econômicas. O objetivo do presente artigo é, portanto, realizar uma resenha da primeira fase da agenda RBC. Apesar dos diversos resultados controversos obtidos, é provável que a principal contribuição dessa agenda seja de cunho metodológico, uma vez que a pesquisa daí advinda afetou profundamente as formas de modelagem macroeconômica vigentes hoje em dia.

Palavras-chave: ciclos de negócios; macroeconomia novo-clássica; expectativas racionais; modelos de ciclos reais de negócios

Código JEL: E10, E13, E32

\section{EQUILIBRIUM AND CYCLES}

ABSTRACT The research agenda related to Real-Business-Cycle models (RBC) has shown a remarkable growth since its beginning, in the eighties. The first models of this kind departed from simple economies without imperfections and tried to explain short-run macroeconomic movements (cycles) from Walrasian general-equi-

* Artigo recebido em 21 de setembro de 2004 e aprovado em 19 de setembro de 2005. O autor agradece os comentários e as sugestões de Afonso Ferreira, Anderson Schneider, Denisard Alves, Fábio Kanczuk e Paulo Picchetti. Um agradecimento especial a Fernando Postali, Gílson Geraldino Jr. e a três pareceristas anônimos desta revista, que forneceram diversas sugestões específicas a uma versão anterior do texto que muito contribuíram na confecção da versão atual. O autor agradece ainda o apoio financeiro da Sasakawa Young Leader Foundation Fellowship (SYLFF), embora valha a ressalva de que as opiniões aqui contidas não refletem, de modo algum, as opiniões desse órgão ou de algum de seus membros. Do mesmo modo, os erros e idiossincrasias que ainda fizerem com que este trabalho não represente uma resposta ótima de equilíbrio aos incentivos vigentes na economia devem-se única e exclusivamente ao autor.

** Mestre em Teoria Econômica pelo IPE-USP, e-mail: matt@usp. br 
librium settings. Nowadays, RBC models are widely used in Macroeconomics, with a special emphasis on the quantitative aspects of economic fluctuations. The main goal of this paper is to provide a survey of the first stage of the RBC research agenda, since there is not a systematic survey of this literature available in Portuguese. Although there are several controversial results related to RBC models, its main contribution seems to be methodological, since these models had a profound impact on current macroeconomic modeling.

Key words: business cycles; new classical macroeconomics; rational expectations; real-business-cycle models 
I think it is fairly clear that there is nothing in the behavior of observed economic time series which precludes ordering them in equilibrium terms, and enough theoretical examples exist to lend confidence to the hope that this can be done in an explicit and rigorous way.

ROBERT E. LUCAS JR., Understanding Business Cycles

The match between theory and observation is excellent, but far from perfect.

EDWARD C. PRESCOTT

Theory Ahead of Business Cycle Measurement

\section{INTRODUÇÃO}

Em outubro de 1995, a Academia Real de Ciências da Suécia conferiu o Prêmio Nobel de Economia a Robert E. Lucas Jr., da Universidade de Chicago. A razão para tal premiação deveu-se principalmente a suas contribuições realizadas ao longo da década de 1970, relacionadas à macroeconomia de curto prazo, em especial, ao estudo dos ciclos de negócios. É praticamente impossível, hoje em dia, discutir algum tópico dessa área sem fazer algum tipo de referência a Lucas. A obra desse autor influenciou profundamente o pensamento de toda uma geração de macroeconomistas, uma vez que foi elaborada não apenas uma severa crítica à ortodoxia vigente na época, mas também porque foi proposto todo um novo corpo teórico para substituí-la.

Lucas é tido como o fundador da macroeconomia novo-clássica. Muitos avanços, tanto em nível teórico quanto empírico, ocorreram desde então. A própria macroeconomia novo-clássica acabou evoluindo de forma a dar lugar aos chamados "modelos de ciclos reais de negócios" (Real-BusinessCycle models - RBC). ${ }^{1}$ Por outro lado, as críticas dos novo-clássicos à economia keynesiana da década de 1970 podem ser tidas, na sua maioria, como responsáveis pelo surgimento do novo-keynesianismo. ${ }^{2}$

Menos de dez anos depois da premiação de Lucas, em 2004 a Academia sueca premiou Finn Kydland, da Universidade da Califórnia em Santa Bárbara, e Edward C. Prescott, da Universidade Estadual do Arizona, por suas contribuições para a macroeconomia, especialmente por seus trabalhos relacionados a modelos RBC e ao desenho e à implementação de políticas econômicas. ${ }^{3}$ No início da década de 1980 , esses economistas começaram a trabalhar com modelos correspondentes a versões estocásticas do modelo 
neoclássico de crescimento como forma de explicar as flutuações de curto prazo da economia. Ou seja, partindo de um instrumental de análise no longo prazo, procuravam explicar o desempenho da economia no curto prazo, uma tarefa ambiciosa cujos esforços remontam pelo menos até a obra de Schumpeter.

Os modelos RBC iniciais eram extremamente simples, sendo compostos em geral por um agente representativo atuando em uma economia artificial sem imperfeições e que maximizava uma função-utilidade intertemporal, estando sujeito a restrições de recursos (também intertemporais). A principal questão implícita nesses trabalhos era a seguinte: qual seria a parcela das flutuações ocorridas nessas economias que poderia ser atribuída somente a fatores reais (como choques de produtividade, por exemplo), em vez de fatores nominais (como a moeda), tidos até então como o principal fator gerador dos ciclos de negócios? Para a surpresa de diversos economistas da época, esses modelos simples conseguiam replicar boa parte dos fatos estilizados dos ciclos de negócios da economia norte-americana. Era o surgimento da agenda de pesquisa relacionada a modelos RBC.

A possibilidade de se modelar um fenômeno aparentemente errático (como os ciclos) a partir de um arcabouço de equilíbrio não apenas constituiu um avanço metodológico, mas também permitiu um maior grau de aproximação entre as teorias micro e macroeconômica, algo desejável, uma vez que poderia fornecer, à primeira vista, um maior grau de coerência interna à disciplina como um todo. Além disso, levando-se em conta a crítica de Lucas (1976) à modelagem econométrica vigente até a década de 1970, tem-se que a fundamentação microeconômica de relações agregadas poderia equivaler a uma forma de se obterem conclusões robustas em termos de política econômica.

Nos últimos anos, a metodologia $\mathrm{RBC}$ vem sendo empregada no Brasil por meio de estudos que buscam descrever os principais fatos estilizados dos ciclos de negócios no país, bem como verificar a adequação de modelos do gênero ao contexto nacional. Entretanto, pouco tem sido feito no sentido de divulgar algumas das idéias e conceitos subjacentes a esse tipo de análise. Este é o principal objetivo do presente artigo: realizar uma sistematização em português de parte dessa literatura. As vantagens desse tipo de empreendimento são duas, basicamente: primeiro, atrair um maior volume de pes- 
quisa para a área; segundo, evitar caracterizações enganosas tanto a respeito das hipóteses quanto dos principais resultados advindos de modelos RBC.

Atualmente, a agenda de pesquisa RBC é muito extensa para poder ser resumida em um artigo sujeito a restrições de tamanho, conforme é o caso presente. Levando-se isto em conta, a presente análise concentra-se na primeira geração de modelos do gênero, apenas. Esperamos que, no futuro, outros autores encarreguem-se de atualizar a presente resenha, incorporando modelos mais recentes. Não há aqui a intenção de descrever contribuições de autores ligados a essa agenda de pesquisa e que estejam relacionadas a outras subáreas da macroeconomia, como questões relacionadas ao desempenho de longo prazo da economia ou a problemas de inconsistência dinâmica, por exemplo. $\mathrm{O}$ foco principal do artigo equivale às flutuações de curto prazo da economia, ou seja, os ciclos de negócios. Há mais de dez anos, Barbosa (1992) realizou uma extensa resenha em português relacionada à primeira fase da macroeconomia novo-clássica, com ênfase nos trabalhos de Lucas, Sargent e outros autores dessa agenda de pesquisa. O presente trabalho pode ser visto como complementar à análise de Barbosa, com a ênfase recaindo, no caso, sobre modelos RBC. Do mesmo modo, o artigo pretende realizar uma revisão deliberadamente parcial e pouco formalizada da literatura RBC, buscando, em última instância, providenciar uma caracterização preliminar de modelos do gênero que seja acessível a economistas não familiarizados com a área. Em certo sentido, este artigo representa mais uma contribuição em termos da história do pensamento econômico do que da macroeconomia propriamente dita.

De qualquer forma, este esforço de pesquisa poderá servir como base para uma caracterização inicial dessa agenda, até mesmo porque a maior parte das aplicações de modelos RBC ao contexto brasileiro vem se baseando em modelos de primeira geração (ver Kanczuk e Faria, 2000; Val e Ferreira, 2001; Ellery, Gomes e Sachshida, 2002, por exemplo). E as possibilidades futuras são muitas, no caso. Primeiro, a pesquisa futura pode vir a seguir na linha RBC tradicional, trabalhando com economias artificiais e incorporando novas hipóteses a modelos pré-existentes à medida que isso for necessário, nas linhas propostas por Prescott (1998). Segundo, há também a possibilidade de se testar empiricamente a adequação desses modelos a partir do uso de técnicas econométricas, seguindo algumas das sugestões contidas em Eichenbaum (1991), por exemplo. 
O artigo está dividido da seguinte maneira: na seção 1, expomos alguns dos principais fatos estilizados relacionados a ciclos de negócios e crescimento, como forma de contextualizar os desenvolvimentos posteriores. $\mathrm{Na}$ seção 2, tratamos brevemente da contribuição metodológica de Lucas para a agenda RBC como um todo. Na seção 3, descrevemos as abordagens pioneiras dessa agenda, a saber, as contribuições de Kydland e Prescott (1982), Long e Plosser (1983) e Prescott (1986a). Na seção 4, descrevemos as críticas iniciais a modelos RBC, tanto de caráter teórico quanto empírico. A seção 5 trata das aplicações de modelos do gênero ao contexto brasileiro, ao mesmo tempo em que ressalta alguns dos problemas associados a esse tipo de empreendimento. Finalmente, na última seção são apresentadas as conclusões do trabalho.

\section{FATOS ESTILIZADOS}

Uma das preocupações básicas de diversos macroeconomistas ao longo do tempo relaciona-se à possibilidade de criação de uma abordagem unificada entre teorias do ciclo e do crescimento. Afinal de contas, seria interessante obter uma teoria que pudesse abranger, ao mesmo tempo, fenômenos distintos à primeira vista, mas que possuíssem uma ligação comum, conforme é o caso das flutuações (ciclos) e do crescimento. ${ }^{4}$

E é exatamente essa a proposta dos pesquisadores ligados à agenda RBC: fornecer uma abordagem unificada desses dois fenômenos. No caso, esses autores elaboram modelos que equivalem a versões modificadas do modelo neoclássico de crescimento (Solow, 1956). Para tanto, acabam tendo de modificá-lo de forma a terem uma fonte de choques incidentes sobre a economia artificial ou, do contrário, o modelo tenderá a convergir, por construção, para um patamar de crescimento equilibrado. Do mesmo modo, devem passar a considerar variações do nível de emprego, dada a importância dessa variável no caso de horizontes curtos de tempo, conforme é ilustrado na tabela 1, que exibe as contribuições dos fatores de produção (capital e trabalho) e da produtividade no curto e no longo prazos.

Os resultados na tabela 1 fornecem a base para as características ideais que deve ter um modelo que busque explicar simultaneamente os fenômenos de ciclo e crescimento. Em termos de altas freqüências (ciclos), o fator 
Tabela 1: Contribuições dos fatores capital e trabalho e da produtividade para o crescimento e os ciclos de negócios

\begin{tabular}{lcc}
\hline Mudanças no produto per capita & Crescimento & Ciclo \\
\hline Devidas a variações no capital & $1 / 3$ & 0 \\
\hline Devidas a variações no trabalho & 0 & $2 / 3$ \\
\hline Devidas a variações na produtividade & $2 / 3$ & $1 / 3$ \\
\hline
\end{tabular}

Fonte: Cooley e Prescott (1995: 11).

trabalho revela-se como responsável pela maior parte das variações no produto per capita, com a parcela restante dessas variações podendo ser atribuída à produtividade. Nessas freqüências, as variações devidas ao fator capital são praticamente desprezíveis. Por outro lado, no caso de baixas freqüências (crescimento), a participação do trabalho é praticamente nula, com a maior parte das variações no produto passando a ocorrer em função de variações na produtividade. Adicionalmente, também é necessário atentar para as regularidades empíricas (fatos estilizados) desses dois fenômenos conjuntamente, procurando-se adequar os modelos teóricos construídos a essas regularidades como forma de se obter uma representação aproximada da realidade.

No caso do crescimento de longo prazo, os principais fatos estilizados (também conhecidos como "fatos estilizados de Kaldor") podem ser sumarizados da seguinte maneira (Barro e Sala-i-Martin, 1995: 5):

(1) O produto per capita cresce ao longo do tempo, com sua taxa de crescimento não tendendo a diminuir.

(2) O estoque de capital físico por trabalhador cresce ao longo do tempo.

(3) A taxa de retorno do capital é aproximadamente constante.

(4) A razão entre capital físico e produto é aproximadamente constante.

(5) As parcelas (shares) dos fatores capital e trabalho na renda nacional são aproximadamente constantes.

(6) A taxa de crescimento do produto por trabalhador varia de forma substancial entre países.

Em relação aos ciclos de negócios, os principais fatos estilizados relacionados a esse fenômeno são os seguintes (Cooley e Prescott, 1995; Cooley e Hansen, 1995):

(1) As magnitudes das flutuações no produto e nas horas de trabalho agregadas são aproximadamente iguais. 
(2) Apesar de o emprego flutuar aproximadamente tanto quanto o produto e as horas de trabalho agregadas, o número médio de horas semanais flutua consideravelmente menos, o que sugere que a maior parte das flutuações ocorridas no número total de horas trabalhadas deve-se a movimentos dentro e fora da força de trabalho (a chamada "margem extensiva"), em vez de ajustes nas horas médias de trabalho ("margem intensiva").

(3) O consumo de bens não duráveis e de serviços apresenta um padrão suave, com flutuações consideravelmente menores do que o produto.

(4) O investimento em bens duráveis apresenta flutuações consideravelmente superiores às flutuações do produto.

(5) O estoque de capital flutua menos que o produto, sendo pouco correlacionado com essa variável.

(6) A produtividade é tida como levemente pró-cíclica, embora varie consideravelmente menos que o produto.

(7) Os salários variam menos que a produtividade ao longo do ciclo.

(8) A correlação entre a remuneração média por hora de trabalho e o produto é praticamente nula.

(9) A correlação entre os gastos do governo e o produto é praticamente nula.

(10) Importações são mais fortemente pró-cíclicas do que exportações.

(11) Os agregados monetários e a velocidade-renda da moeda são prócíclicos.

(12) A correlação entre o produto e o nível de preços é negativa. ${ }^{5}$

(13) As correlações tanto entre o produto e as taxas de inflação quanto entre o produto e as taxas de juros nominais são ambas positivas.

Na tabela 2 expomos alguns dos principais fatos estilizados dos ciclos de negócios para a economia americana. ${ }^{6}$

Apesar da longa extensão da tabela 2, é impressionante notar como é possível extrair uma riqueza de informações relevantes referentes a uma dada economia a partir de estatísticas tão simples à primeira vista, como aquelas reportadas na tabela. No caso, o desvio-padrão de cada variável equivale a uma medida de volatilidade, ao passo que os valores reportados para os coeficientes de correlação na tabela registram o grau de associação 
Tabela 2: Padrão cíclico de variáveis macroeconômicas selecionadas, Estados Unidos (1954:01-1991:02)

\begin{tabular}{|c|c|c|c|c|}
\hline \multirow[t]{2}{*}{ Variável } & \multirow[t]{2}{*}{ Desvio-padrão (\%) } & \multicolumn{3}{|c|}{ Correlação cruzada com o produto } \\
\hline & & $x(-1)$ & $x$ & $x(+1)$ \\
\hline PNB & 1.72 & .85 & 1.00 & .85 \\
\hline CONS & 1.27 & .82 & .83 & .67 \\
\hline CNDS & .86 & .78 & .77 & .64 \\
\hline CDS & 4.96 & .75 & .78 & .61 \\
\hline INV & 8.24 & .79 & .91 & .76 \\
\hline INVF & 5.34 & .82 & .90 & .81 \\
\hline Ch. INV & 17.3 & .53 & .67 & .51 \\
\hline GOVT & 2.04 & -.01 & .04 & .08 \\
\hline EXP & 5.53 & .15 & .37 & .50 \\
\hline IMP & 4.88 & .62 & .72 & .71 \\
\hline HSHOURS & 1.59 & .74 & .86 & .82 \\
\hline HSAVGHRS & .63 & .63 & .62 & .52 \\
\hline HSEMPLMT & 1.14 & .69 & .85 & .86 \\
\hline GNP/HSHOURS & .90 & .33 & .41 & .19 \\
\hline WAGE & .76 & .66 & .68 & .59 \\
\hline COMP & .55 & .09 & .03 & -.07 \\
\hline CPI & 1.43 & -.65 & -.52 & -.35 \\
\hline INFL & .57 & .19 & .34 & .43 \\
\hline MB & .84 & .37 & .30 & .21 \\
\hline M1 & 1.52 & .39 & .33 & .21 \\
\hline M2 & 1.46 & .50 & .33 & .10 \\
\hline M1V & 1.94 & .15 & .37 & .39 \\
\hline GB10YR & .66 & -.09 & .10 & .08 \\
\hline TB1MO & 1.29 & .20 & .40 & .42 \\
\hline
\end{tabular}

Fontes: Cooley e Prescott (1995: 30-31) e Cooley e Hansen (1995: 180-181).

Notas:

(1) Os dados usados para calcular as estatísticas acima possuem periodicidade trimestral, englobando o período 1954:1-1991:2. Todos os dados estão em escala logarítmica, tendo sido suavizados pelo filtro de Hodrick-Prescott (Hodrick e Prescott, 1997).

(2) O significado das variáveis na tabela é o seguinte: PNB - produto nacional bruto norte-americano a dólares de 1982; CONS gastos pessoais em consumo a dólares de 1982; CNDS - consumo de bens não duráveis e serviços a dólares de 1982; CDS consumo de bens duráveis a dólares de 1982; INV - investimento bruto privado a dólares de 1982; INVF - investimento fixo a dólares de 1982; Ch. INV - variação em estoques a dólares de 1982; GOVT - gastos do governo com bens e serviços a dólares de 1982; EXP - volume de exportaçōes de bens e serviços a dólares de 1982; IMP - volume de importações de bens e serviços a dólares de 1982; HSHOURS - total de horas trabalhadas (Household Survey); HSAVGHRS - horas semanais médias (Household Survey); HSEMPLMT - nível de emprego (Household Survey); GNP/HSHOURS - produtividade do trabalho; WAGE - salário médio/ hora a dólares de 1982; COMP - compensação média total/hora a dólares de 1982; CPI - índice de preços ao consumidor; INFL - primeira-diferença do logaritmo de CPI; MB - base monetária; M1, M2 - agregados monetários; M1V - velocidade-renda de M1; GB10R - títulos do governo com maturação de dez anos; TB1MO - títulos do Tesouro americano com maturação de um mês. 
linear de cada variável com o nível de renda, bem como sua direção de movimento ao longo do ciclo e o timing das oscilações. Assim, podemos notar que os fatos estilizados descritos acima são confirmados no caso das estatísticas reportadas na tabela. O consumo agregado, por exemplo, apresenta menor volatilidade que o produto (desvio-padrão de 1.27), ao mesmo tempo em que exibe um padrão pró-cíclico e coincidente (coeficiente de correlação contemporânea de .83). O investimento, por sua vez, é nitidamente mais volátil do que o produto (desvio-padrão de 8.24), também exibindo um padrão pró-cíclico e coincidente (coeficiente de correlação contemporânea de .91). Um raciocínio semelhante vale para as demais variáveis contidas na tabela. Dada a sua utilidade, esse tipo de informação passou a ser amplamente usado em modelos RBC, tanto no sentido de motivar extensões de modelos propostos quanto no de ressaltar enigmas empíricos relacionados a essa agenda de pesquisa.

A descrição dos fatos estilizados de curto e longo prazos pode ser vista como uma forma de verificar a adequação de diferentes modelos à realidade. No caso específico de uma abordagem que se submeta à tarefa ambiciosa de explicar ambos os fenômenos (ciclo e crescimento) conjuntamente, passa a ser necessário gerar modelos que sejam condizentes, ao mesmo tempo, com ambos os tipos de evidência. E foi exatamente nessa direção que caminharam os primeiros esforços de pesquisa da agenda RBC.

\section{A CONTRIBUIÇÃo METOdOLÓGICA DE LUCAS}

Lucas pode ser tido como o principal responsável pelo revival do estudo dos ciclos de negócios a partir do início da década de 1970. Em um artigo clássico sobre o tema, intitulado "Understanding business cycles" (Lucas, 1977), o autor atenta para a possibilidade de se obter uma explicação unificada para esse fenômeno:

(...) business cycles are all alike. To theoretically inclined economists, this conclusion should be attractive and challenging, for it suggests the possibility of a unified explanation of business cycles, grounded in the general laws governing market economies, rather than in political or institutional characteristics specific to particular countries or periods. (Lucas, 1977: 10, grifos do autor) 
Esta última afirmação de Lucas tem um caráter, no mínimo, controverso. Se, por um lado, parece extremamente estimulante em termos intelectuais a possibilidade de se obter uma explicação genérica para um fenômeno à primeira vista tão errático e imprevisível quanto o ciclo de negócios, por outro, parece problemático desconsiderar especificidades históricas, institucionais e políticas de diferentes países quando da análise desse fenômeno.

Apesar de ter diversas contribuições substantivas relacionadas ao estudo dos ciclos de negócios, uma das principais contribuições de Lucas é de cunho metodológico. ${ }^{7}$ Algumas de suas recomendações nesse sentido podem ser resumidas a partir de afirmações do tipo:

One exhibits understanding of business cycles by constructing a model in the most literal sense: a fully articulated artificial economy which behaves through time so as to imitate closely the time series behavior of actual economies. (Lucas, 1977: 11, grifo do autor)

Em ocasião posterior, no seu "Methods and problems in business cycle theory" (Lucas, 1980), esse autor expõe de forma mais detalhada sua visão sobre o papel da teoria no estudo dos ciclos de negócios. Para ele, o papel da teoria econômica é o seguinte:

One of the functions of theoretical economics is to provide fully articulated, artificial economic systems that can serve as laboratories in which policies that would be prohibitively expensive to experiment with in actual economies can be tested out at much lower cost. To serve this function well, it is essential that the artificial 'model' economy be distinguished as sharply as possible in discussion from actual economies. (...) Though we are interested in models because we believe they may help us to understand matters about which we are currently ignorant, we need to test them as useful imitations of reality by subjecting them to shocks for which we are fairly certain how actual economies, or parts of economies, would react. The more dimensions on which the model mimics the answers actual economies give to simple questions, the more we trust its answers to harder questions. This is the sense in which more "realism' in a model is clearly preferred to less.

Assim, para o autor, o significado do termo "teoria” é o seguinte:

On this general view of the nature of economic theory then, a "theory" is not a collection of assertions about the behavior of the actual economy but rather an explicit set of instructions for building a parallel or analogue system - a mechanical, imitation economy. A "good" model, from this point 
of view, will not be exactly more 'real' than a poor one, but will provide better imitations. Of course, what one means by a 'better imitation' will depend on the particular questions to which one wishes answers. (Lucas, 1980: 697)

Basicamente, o autor defende que modelos, sendo abstrações da realidade, por definição, não deveriam ser julgados em termos do realismo de suas hipóteses, mas sim em termos da forma como "imitam" economias reais em certas dimensões. $\mathrm{O}$ autor possui uma visão bastante pragmática do papel da teoria econômica, justificando essa posição a partir do fato de que experimentos sociais realizados em escala macroeconômica são tidos como custosos e inconcebíveis.

Em termos da adequação empírica desses modelos, Lucas fornece sugestões que acabariam por constituir a base dos procedimentos de verificação empírica dos modelos RBC. Em relação aos parâmetros desses modelos, o autor diz o seguinte:

On these parameters, we have a wealth of inexpensively available data from census cohort information, from panel data describing the reactions of individual households to a variety of changing market conditions, and so forth. In principle (...) these crucial parameters can be estimated independently from individual as well as aggregate data. If so, we will know what the aggregate parameters mean, we will understand them in a sense that disequilibrium adjustment parameters will never be understood. This is exactly why we care about the 'microeconomic foundations' of aggregate theories. (Lucas, 1980: 712, grifo do autor)

As recomendações metodológicas contidas em Lucas $(1977,1980)$ exerceram um tremendo impacto sobre a geração de economistas na década de 1980. Suas instruções eram simples e claras: macroeconomistas deveriam começar a construir economias artificiais, a partir das quais pudessem executar simulações com cenários econômicos alternativos, dado o alto custo dessas simulações na prática. Os parâmetros necessários a essas simulações, por sua vez, poderiam ser obtidos a partir de estudos microeconométricos ou informações agregadas preexistentes. Uma conseqüência direta dessas recomendações foi que boa parte da pesquisa relacionada a ciclos de negócios realizada a partir da década de 1980 passou a basear-se rigidamente nessas instruções metodológicas. ${ }^{8}$ 


\section{CHOQUES REAIS E MECANISMOS DE PROPAGAÇÃO:}

\section{AS ABORDAGENS SEMINAIS DA AGENDA DE PESQUISA RBC}

Dado o benefício de uma visão retrospectiva, podemos considerar, hoje em dia, três trabalhos como contribuições seminais da agenda RBC. São eles: Kydland e Prescott (1982), Long e Plosser (1983) e Prescott (1986a). ${ }^{9}$

Antes, no entanto, vale a pena discorrermos brevemente sobre alguns dos principais conceitos empregados geralmente nesses modelos, como os conceitos de "equilíbrio" e "choque tecnológico". Do mesmo modo, expomos abaixo um modelo estilizado simples com o objetivo de facilitar a compreensão posterior dos modelos descritos nesta seção.

Apesar de inicialmente o termo "equilíbrio" ser usado para descrever a igualdade entre oferta e demanda em um dado instante (ou seja, um conceito estático), seu significado mudou ao longo do tempo. ${ }^{10} \mathrm{Na}$ verdade, esse conceito pode não ser útil quando pensamos em ambientes dinâmicos, onde a economia sofre simultaneamente os efeitos de diversos choques. No caso, alguns economistas acabaram desenvolvendo um conceito dinâmico de equilíbrio, onde os agentes econômicos formulam regras de decisão (ou "planos de contigência") de acordo com a informação disponível. Teoricamente, o termo "equilíbrio" passou a ser usado para descrever o ponto de repouso do espaço de regras de decisão dos agentes, o que possibilitou, em última instância, o uso desse conceito para a análise de ambientes onde fatores como a dinâmica e a incerteza são fundamentais. Neste sentido, passa a ser possível descrever fenômenos tidos à primeira vista como "desequilíbrios" (tais como os ciclos e o desemprego, por exemplo), a partir de um arcabouço de equilíbrio. É neste sentido que o termo é usualmente empregado nessa literatura.

O conceito de choque tecnológico (ou de produtividade) empregado, por sua vez, pode refletir diversos fatores além daqueles estritamente ligados à inovação tecnológica. Pode refletir, por exemplo, choques de oferta em um sentido mais genérico, como variações climáticas ou aumentos de preço dos insumos de produção. Também pode vir a refletir fatores institucionais, como mudanças no sistema político de um país. O ponto importante a ser retido é que o termo genérico "choque tecnológico" equivale ao conjunto de fatores tidos como fora da influência das firmas individuais da economia (Hansen, 1994: 4). 
Os primeiros modelos RBC possuíam uma estrutura relativamente simples. ${ }^{11}$ Em geral, considerava-se que todas as decisões dos agentes da economia pudessem ser descritas a partir das decisões de um agente representativo que vive infinitamente e que maximiza uma função utilidade do seguinte tipo:

$$
E \sum_{t=0}^{\infty} \beta^{t} u\left(C_{t}, L_{\mathrm{t}}\right)
$$

onde $C_{t}$ e $L_{t}$ representam o consumo e o lazer do agente, respectivamente. A hipótese de que o agente vive indefinidamente pode ser vista como uma situação em que os agentes preocupam-se com o bem-estar de gerações futuras (embora preocupem-se mais com o bem-estar da geração presente, $o$ que é denotado a partir da taxa de desconto intertemporal $\beta, \operatorname{com} 0<\beta<1$ ).

A dotação inicial de tempo do agente pode ser normalizada para a unidade, tendo-se que $L_{t}+N_{t}=1$, onde $N_{t}$ representa o fator trabalho (número de horas trabalhadas pelo agente). Essa última expressão pode ser vista como a restrição de tempo do agente. Outra restrição com a qual o agente se defronta é a seguinte:

$$
C_{t}+I_{t} \leq Y_{t}
$$

Ou seja, o agente representativo dessa economia pode alocar sua renda entre consumo, $C_{t}$ e/ou investimento, $I_{t}$ (caso de uma economia fechada e sem governo). Especificamente, vale a seguinte relação:

$$
C_{t}+I_{t}=F\left(Z_{t}, K_{t}, N_{t}\right)=r_{t} K_{t}+w_{t} N_{t}
$$

onde a produção pode ser representada a partir de uma tecnologia descrita pela função $F($.$) , com K_{t}$ e $N_{t}$ denotando os fatores capital e trabalho, respectivamente. $\mathrm{O}$ termo $Z_{t}$ denota um índice agregado da tecnologia vigente na economia. Os termos $r$ e $w$ equivalem às remunerações dos fatores capital e trabalho (taxas de aluguel e salários). Considera-se a existência de mercados competitivos, com o agente tomando os preços ( $r$ e $w$, no caso) como dados. $\mathrm{O}$ agente representativo defronta-se com o problema de maximizar a função-utilidade (1), sujeito à restrição de recursos descrita em (2'), com essa restrição sendo válida ao longo do tempo.

As firmas dessa economia também atuam em um ambiente competitivo, buscando maximizar a seguinte função-lucro: 


$$
F\left(Z_{t}, K_{t}, N_{t}\right)-r_{t} K_{t}-w_{t} N_{t}
$$

A evolução do estoque de capital da economia, por sua vez, é descrita a partir da seguinte lei de movimento:

$$
K_{t+1}=(1-\delta) K_{t}+I_{t}
$$

onde $K_{t}$ e $K_{t+1}$ representam, respectivamente, os estoques de capital dos períodos atual e futuro da economia, enquanto o termo $I_{t}$ representa investimento.

O choque tecnológico incidente sobre a economia pode ser descrito a partir de um processo auto-regressivo de primeira ordem (AR[1]):

$$
Z_{t+1}=\rho Z_{t}+\varepsilon_{t+1}
$$

com $Z_{t}$ representando o choque tecnológico, enquanto que $\varepsilon_{t}$ equivale ao componente, aleatório desse choque ("inovações"), sendo independente e identicamente distribuído ao longo do tempo, com média zero e variância constante, $\sigma^{2}\left(\varepsilon_{t} \sim\right.$ i.i.d. $\left.\left[0, \sigma^{2}\right]\right)$. O termo $\rho$ capta a persistência do choque tecnológico, sendo considerado, em geral, como tendo um valor menor ou igual à unidade $(0<\rho \leq 1)$.

Enquanto a equação (1) representa o lado das famílias dessa economia (via descrição de suas preferências em termos agregados), a função de produção $F($.) e a equação (3) denotam o lado das firmas. O aspecto dinâmico do modelo é representado pelas leis de movimento descritas a partir das equações (4) e (5). Choques tecnológicos afetam as decisões agregadas do agente representativo, acabando por gerar oscilações semelhantes a ciclos nas variáveis consumo, investimento, produção e horas trabalhadas. É partindo de esquemas simplificados como este que os modelos RBC iniciais buscavam analisar os efeitos de choques reais sobre a economia.

Kydland e Prescott (1982) partem de uma versão modificada do modelo neoclássico de crescimento, com choques de produtividade incidentes sobre uma economia sem imperfeições e com um agente representativo com expectativas racionais. Adicionalmente, os autores fazem duas hipóteses básicas relacionadas aos mecanismos de propagação de choques pela economia, que são as seguintes:

(a) Projetos de investimento em capital tornam-se plenamente produtivos apenas após um certo período de tempo, no caso, quatro trimestres (hipótese "time-to-build"). ${ }^{12}$ 
(b) O lazer do agente na função utilidade é representado a partir de uma combinação de horas de lazer dos períodos atual e passado. ${ }^{13}$

No modelo, o agente apenas observa um indicador de produtividade e, com base nesse indicador e em outras variáveis agregadas, toma decisões relacionadas ao volume de investimento a ser feito na economia, bem como à quantidade de tempo alocada na produção de bens.

Modelos como esse não possuem solução analítica, com o procedimento padrão de resolução equivalendo ao uso de técnicas de aproximação numérica. Seguindo as recomendações de Lucas (1980), os valores dos parâmetros do modelo são escolhidos a partir de resultados de estudos microeconométricos, observações relacionadas ao crescimento de longo prazo e valores presentes nas Contas Nacionais. No caso, o pesquisador, baseado em informações preexistentes, escolhe valores para os principais parâmetros do modelo. Assim, Kydland e Prescott (1982: 1.363, tabela 1) reportam valores específicos para os principais parâmetros relacionados a formas funcionais específicas de expressões como (1), (2), (2'), (4) e (5) descritas acima. Os demais parâmetros livres do modelo são escolhidos de modo a gerarem uma correspondência — tão próxima quanto possível — entre as economias real e artificial em termos das estatísticas supracitadas. Esse processo de escolha de parâmetros em modelos RBC ficou conhecido como "calibração", sendo também usado em outras áreas da economia.

Então, a partir de um programa de computador, é construída uma economia artificial, onde os dados gerados são logaritmizados e filtrados pelo procedimento de Hodrick-Prescott (Hodrick e Prescott, 1997), ${ }^{14}$ além de se considerar uma economia com o mesmo número de períodos da economia real. Em seguida, são feitas simulações onde o computador gera várias séries de valores distintos do choque tecnológico - medido via o desvio-padrão de um índice de produtividade calculado para a economia real, no caso que incidem sobre a economia artificial, o que resulta em diversas trajetórias para as séries artificiais do modelo, para então serem calculadas médias de estatísticas relacionadas a essas simulações. Faz-se isto de modo a facilitar a comparação entre as economias real e artificial. ${ }^{15}$

A adequação empírica do modelo é feita a partir da comparação dos segundos momentos (desvios-padrão e coeficientes de correlação) das economias real e artificial. Quanto mais próximos forem esses valores, melhor 
será o ajuste do modelo, com a economia artificial sendo capaz de "imitar" de maneira acurada o comportamento da economia real em questão. Por outro lado, valores destoantes dessas estatísticas apontam para a necessidade de modificações no modelo original.

Valendo-se dos métodos de solução descritos acima, os autores simulam uma economia artificial, comparando seus resultados com estatísticas calculadas para os Estados Unidos ao longo do período 1950-1979. Seus resultados são ilustrados na tabela 3 .

No caso dessa tabela, o valor do desvio-padrão para os níveis de produto das duas economias consideradas (a real e a artificial) é o mesmo, pois a variância do choque de produtividade incidente sobre as variáveis do modelo é escolhida de modo a garantir a condição de que a volatilidade da série de produto gerada seja igual à volatilidade do produto na economia real. ${ }^{16}$

De acordo com os resultados contidos na tabela 3, podemos observar que as variáveis agregadas da economia artificial apresentam um padrão

Tabela 3: Resultados de Kydland e Prescott (1982) para a economia americana

\begin{tabular}{lcccc}
\hline Variável & \multicolumn{2}{c}{ Economia americana } & \multicolumn{2}{c}{ Economia artificial } \\
& $(\mathrm{a})$ & $(\mathrm{b})$ & $(\mathrm{a})$ & $(\mathrm{b})$ \\
\hline Produto real & 1.8 & 1.00 & $(.23)$ & 1.00 \\
\hline Consumo & 1.3 & .74 & .63 & .94 \\
& & & $(.09)$ & $(.01)$ \\
\hline Investimento & 5.1 & .71 & 6.45 & .80 \\
& & & $(.62)$ & $(.04)$ \\
\hline Estoques & 1.7 & .51 & 2.00 & .39 \\
& & & $(.20)$ & $(.06)$ \\
\hline Capital & .7 & -.24 & .63 & -.07 \\
& & & $(.08)$ & $(.06)$ \\
\hline Horas & 2.0 & .85 & 1.05 & .93 \\
& & & $(.13)$ & $(.01)$ \\
\hline Produtividade & 1.0 & .10 & .90 & .90 \\
& & & $(.10)$ & $(.02)$ \\
\hline
\end{tabular}

Fonte: Kydland e Prescott (1982: 1.364-1.365, tabelas 3 e 4 ).

Notas:

(1) Os dados usados para calcular as estatísticas acima possuem periodicidade trimestral, englobando o período 1950:1-1979:2. Todos os dados estão em escala logarítmica, tendo sido suavizados pelo filtro de Hodrick-Prescott.

(2) A coluna (a) corresponde aos valores dos desvios-padrão calculados para as variáveis consideradas, expressos em percentagem.

(3) A coluna (b) exibe a correlação de cada variável com o produto real.

(4) O termo horas serve para designar o total de horas trabalhadas na economia, representando o fator trabalho, no caso.

(5) No caso da economia artificial, valores em parênteses equivalem aos erros-padrão das estatísticas calculadas. 
qualitativo semelhante ao da economia real. O consumo, por exemplo, é menos volátil do que o produto (valores do desvio-padrão de 1.3 e .63 nas economias real e artificial, respectivamente), apresentando um padrão prócíclico (coeficientes de correlação de .74 e .94, respectivamente). O investimento, por sua vez, é cerca de três vezes mais volátil do que o produto em ambas as economias, também apresentando um padrão pró-cíclico. Essas variáveis apresentam, no caso da economia simulada, um padrão bastante similar ao da economia real, ressaltando tanto o padrão suave do consumo quanto o comportamento volátil do investimento no curto prazo, dois fatos estilizados importantes dos ciclos de negócios. Apesar do bom ajuste qualitativo da maior parte das variáveis da economia artificial, ainda persistem algumas diferenças em termos quantitativos, conforme é o caso das variáveis consumo, horas e produtividade. Segundo a metodologia RBC, são destoâncias desse tipo que acabam por sugerir a necessidade de modificações do modelo em questão. De qualquer forma, a partir de um modelo relativamente simples, Kydland e Prescott conseguiram obter resultados surpreendentes, com a economia artificial por eles criada exibindo um padrão cíclico semelhante em algumas dimensões com a economia americana ao longo do período considerado.

Apesar de sua adequação empírica relativamente boa — segundo o critério proposto pelos autores —, o modelo de Kydland e Prescott (1982) ainda deixava algumas questões relevantes em aberto: primeiramente, como explicar a ocorrência de choques tecnológicos em escala agregada, capazes de afetar a economia como um todo (já que choques de produtividade equivaliam à única fonte de flutuações em seu modelo)? Outro problema dizia respeito ao mercado de trabalho: no caso, flutuações no emprego eram vistas como respostas ótimas dos agentes aos choques incidentes na economia artificial, que fariam variar livremente o montante de horas ofertadas a partir de um processo de substituição intertemporal de trabalho. Entretanto, a evidência empírica relacionada a esse tipo de processo aponta na direção de valores baixos para as elasticidades de substituição intertemporal estimadas (ver Card, 1991, por exemplo). A resolução desses problemas adicionais já constituiria, por si só, motivação suficiente para a elaboração de modelos mais refinados.

Uma abordagem distinta à de Kydland e Prescott (1982) é a de Long e Plosser (1983). Partindo de um modelo multissetorial da economia, esses 
autores consideram as decisões relacionadas aos planos de consumo e produção de um agente representativo (por eles denominado "Robinson Crusoé"). Além de basearem-se em dados de matrizes insumo-produto, os autores consideram formas funcionais específicas distintas daquelas consideradas originalmente por Kydland e Prescott (1982), realizando simulações para diversos setores da economia americana. Basicamente, esses autores querem demonstrar como choques de produtividade específicos a setores isolados da economia artificial por eles considerada acabam transformando-se em oscilações em torno do steady-state da economia semelhantes a ciclos de negócios. ${ }^{17}$

Long e Plosser (1983) obtiveram um resultado que causou certa controvérsia quando da publicação de seu artigo, dada a visão dominante em termos de política econômica na época. Essa conclusão dizia respeito ao fato de as flutuações econômicas, no caso desse modelo específico, não serem tidas como redutoras de bem-estar social, já que são vistas como um aspecto natural de uma economia de mercado. Por causa desse fato, os autores demonstram certo ceticismo em relação à política econômica como forma de combate às flutuações. Concluem seu artigo da seguinte forma:

(...) although equilibrium Real-Business-Cycle models of the type we suggest are capable of generating business-cycle-like behavior, we do not claim to have isolated the only explanation for fluctuations in real activity. We do believe, however, that models of this type provide a useful, well-defined benchmark for evaluating the importance of other factors (e.g., monetary disturbances) in actual business-cycle episodes. (Long e Plosser, 1983:

68)

Essa ressalva apenas confirma o caráter exploratório das abordagens iniciais sobre o tema, bem como o fato de os autores terem clara consciência das limitações de seu modelo. ${ }^{18}$

Procurando quantificar a importância de choques tecnológicos na geração das flutuações econômicas, Prescott (1986a) utiliza o resíduo de Solow (Solow, 1957) como proxy para choques desse tipo incidentes sobre uma economia artificial. Partindo-se de uma função de produção Cobb-Douglas $Y_{t}=Z_{t} K_{t}^{\theta} N_{t}^{1-\theta}$, temos que o resíduo de Solow pode ser representado pela fórmula:

$$
\Delta z_{t}=\Delta y_{t}-\theta \Delta k_{t}-(1-\theta) \Delta n_{t}
$$


onde os termos $y_{t}, n_{t}$ e $k_{t}$ denotam o logaritmo natural das variáveis produto $(Y)$, trabalho $(N)$ e capital $(K)$, respectivamente (variáveis expressas em primeiras-diferenças). Os termos $\theta$ e $(1-\theta)$ correspondem às participações dos fatores capital e trabalho na renda (assumindo-se um mercado competitivo de fatores de produção, bem como a hipótese de retornos constantes de escala na função de produção agregada). Ou seja, o resíduo equivale à variação percentual do produto menos a variação percentual dos fatores de produção, com estes sendo ponderados por sua participação na renda. Em última instância, o resíduo pode ser visto como uma medida de produtividade, sendo também conhecido como "produtividade total dos fatores" (PTF). ${ }^{19}$

Utilizando uma medida do resíduo de Solow para a economia americana, Prescott analisou os efeitos de um choque tecnológico com as mesmas propriedades estatísticas da medida relacionada à economia real (coeficiente de autocorrelação de primeira ordem e variância das inovações) sobre uma economia artificial. Os resultados obtidos também revelaram-se surpreendentes: no caso, o resíduo de Solow seria responsável por cerca de 75\% das flutuações econômicas nos Estados Unidos ao longo do período pós-guerra. Este resultado gerou bastante controvérsia na época de publicação do artigo, uma vez que parecia favorecer de forma considerável a hipótese acerca da importância de fatores reais na geração de flutuações econômicas, em detrimento de fatores nominais como a moeda, por exemplo, tida até então como extremamente importante nesse processo. ${ }^{20}$

Além dessa conclusão controversa, o autor também conclui que (Prescott, 1986a: 21):

(a) A teoria está à frente da mensuração (daí o título de seu artigo, "Theory Ahead of Business Cycle Measurement"), no sentido de que os desvios remanescentes entre a teoria e os fatos reais poderiam desaparecer caso as variáveis econômicas fossem mensuradas de acordo com a teoria.

(b) Esforços custosos na direção de uma política de estabilização tendem a ser vistos, segundo o autor, como contraproducentes, já que flutuações econômicas, no caso dos modelos em questão, representam respostas ótimas diante da incerteza relacionada à taxa de mudança tecnológica. 
(c) Deve-se atentar não apenas para as flutuações do produto em si, mas também para os determinantes da taxa média de avanço tecnológico.

Até o presente momento, foram descritas as principais hipóteses e os resultados de três dos mais influentes artigos RBC produzidos ao longo da década de 1980. Dado o fato de esses esforços de pesquisa terem resultado em conclusões tão radicais, seria de se esperar que fossem severamente criticados. E foi exatamente isto que ocorreu na época, conforme evidencia o debate Prescott-Summers, exposto abaixo. ${ }^{21}$

\section{CRÍTICAS INICIAIS}

Assim como o volume de produção relacionada à agenda $\mathrm{RBC}$ aumentou consideravelmente com o tempo, o mesmo ocorreu em termos das críticas direcionadas a esses modelos. Por causa desse fato, fazemos abaixo uma divisão das principais críticas feitas desde meados da década de 1980 em críticas teóricas e empíricas, basicamente. Do mesmo modo, expomos alguns dos refinamentos teóricos elaborados em resposta a essas críticas.

\subsection{Críticas teóricas}

Um problema básico relacionado aos modelos RBC descritos até agora diz respeito ao papel dos choques tecnológicos no modelo. Em geral, apesar das distintas formas de caracterização de choques dessa natureza, esses eram tidos como a fonte principal (ou até mesmo única) de flutuações nos primeiros modelos RBC. Além disso, dada a forma de verificação empírica empregada nesses modelos e as conclusões daí advindas, os modelos RBC acabaram por gerar enorme controvérsia no meio acadêmico. Na segunda metade da década de 1980, esses modelos sofreram críticas maciças, especialmente de alguns economistas ligados à tradição macroeconômica keynesiana.

Summers (1986) equivale à primeira dessas críticas, tendo se tornado a mais conhecida. Basicamente, esse autor argumenta que a análise de Prescott (1986a) revela-se falha em quatro níveis: ${ }^{22}$

(a) a escolha dos parâmetros;

(b) a origem dos choques tecnológicos incidentes sobre a economia artificial; 
(c) a ausência de preços;

(d) a ausência de falhas de intercâmbio.

Dos quatro itens citados acima, aquele que se revelou como o mais problemático foi o item (b), podendo ser visto como uma espécie de "calcanhar-de-aquiles" da literatura RBC da época, conforme citam King e Rebelo (2000). Afinal de contas, apesar de períodos de prosperidade poderem estar associados à ocorrência de choques tecnológicos que gerem progresso técnico, como explicar a ocorrência de recessões sem ter de justificá-las com base em um retrocesso tecnológico, um fenômeno tido como inaceitável pela maior parte dos economistas? De acordo com Summers (1986: 25),

(...) the finding that measured productivity frequently declines is difficult to account for technologically. What are the sources of technical regress?

Para esse autor, o uso do resíduo de Solow como proxy para choques tecnológicos em modelos RBC é inadequado, uma vez que tais estimativas podem estar contaminadas pelo que convencionou-se denominar "entesouramento de trabalho" (labor-hoarding, em inglês) na literatura especializada sobre economia do trabalho. Segundo essa última hipótese, a produtividade da economia como um todo tenderia a diminuir ao longo de um período recessivo porque as firmas, receosas em demitir sua mão-de-obra, manteriam alguns de seus trabalhadores ainda empregados, mesmo que não houvesse muito serviço a ser feito, com estes podendo executar serviços que não podem ser facilmente mensurados (como limpeza do estabelecimento e organização de estoques, por exemplo). Em períodos de expansão, essa mão-de-obra "armazenada" passaria a produzir com maior esforço, o que explicaria o aumento do nível de produto sem um aumento correspondente no fator trabalho, superestimando a importância dos choques de produtividade. ${ }^{23}$ Adicionalmente, Summers (1986: 25) apóia-se na evidência contida em Fay e Medoff (1985), em que os autores, a partir de questionários distribuídos a gerentes de diversas firmas manufatureiras americanas, concluem pela ocorrência de labor-hoarding nessas firmas.

Em sua réplica a Summers (1986), Prescott (1986b) argumenta que, em relação à natureza dos choques tecnológicos em seu modelo, tem-se que tais choques não ocorrem de forma larga e abrupta, mas são, na verdade, choques pequenos que ocorrem de forma gradual. $\mathrm{O}$ autor ainda faz uma res- 
salva em relação à elevada proporção da contribuição dos choques tecnológicos:

That theory predicts one factor has a particular nature and magnitude does not imply that theory predicts all other factors are zero. I only claim that technology shocks account for more than half the fluctuations in the postwar period, with a best point estimate near 75 percent. This does not imply that terms of trade, and shocks to the technology of exchange had no effect in that period. (Prescott, 1986b: 29)

Quanto à questão de labor-hoarding levantada por Summers (1986), Prescott (1986b: 32) argumenta que esse fenômeno pode atuar em uma direção contrária àquela sugerida pelo primeiro autor. No caso, pela possibilidade de o fator trabalho ser considerado como um fator quase-fixo de produção, no sentido proposto originalmente por Oi (1962), tem-se que as firmas podem, em geral, armazenar menos trabalho durante recessões. Isto ocorreria, por exemplo, pelo fato de as firmas tornarem-se menos relutantes em despedir funcionários nessas épocas, já que é mais difícil obter emprego ao longo de períodos recessivos. Esse argumento implica que o armazenamento de mão-de-obra exibiria um padrão pró-cíclico (e não contracíclico, conforme o raciocínio contido em Summers, 1986). O autor volta a insistir na posição de que, na época, a teoria ainda encontrava-se à frente da mensuração e que até Summers concorda implicitamente com essa última afirmação:

Summers cannot be attacking the use of competitive theory and the neoclassical growth environment in general. (...) He does not provide criteria for deciding when implications of this model should be taken seriously and when they should not be. My guess is that the reason for skepticism is not the methods used, but rather the unexpected nature of the findings. We agree that labor input is not that precisely measured, so neither is technological uncertainty. In other words, we agree that theory is ahead of business cycle measurement. (Prescott, 1986b: 32)

Mankiw (1989) também critica os resultados de Prescott (1986a), embora suas críticas estejam mais direcionadas à agenda RBC como um todo. Ao questionar algumas das conclusões de Prescott (1986a), Mankiw (1989) calculou taxas de variação do produto e do resíduo de Solow para a economia americana ao longo do período 1948-1985, com a série do resíduo calculada por esse autor exibindo um padrão nitidamente pró-cíclico, apresentando 
tanto variações positivas quanto negativas ao longo do período considerado (Mankiw, 1989: 84, figura 1). Embora no período anterior à análise (início da década de 1940) o resíduo tenha apresentado um crescimento médio de cerca de 7,6\% ao ano - o que poderia levar à conclusão de ocorrência de choques de oferta/produtividade na época - , o autor argumenta que o aumento associado do produto no período deveu-se provavelmente a gastos do governo relacionados à preparação do país para o ingresso na Segunda Guerra Mundial, um fenômeno tido como um choque de demanda, na verdade.

Um aspecto especialmente problemático dos primeiros modelos RBC relaciona-se ao mercado de trabalho, uma vez que esses modelos baseavam-se em mecanismos de propagação que supunham um alto grau de substituição intertemporal de trabalho por parte dos trabalhadores, outra hipótese tida muitas vezes como injustificável por certos autores. Além disso, checandose novamente a tabela 3 acima, que contém os resultados de Kydland e Prescott (1982), podemos notar alguns fatos relacionados a esse mercado, conforme ressaltado por Stadler (1994: 1.757):

(a) O fato de que modelos RBC como o de Kydland e Prescott (1982) prevêem uma volatilidade do fator trabalho bem inferior àquela observada na realidade (cerca de 50\% inferior, no caso). Este fato também é conhecido como o "enigma da variabilidade do emprego".

(b) Se choques tecnológicos realmente causam o ciclo, então as variáveis emprego e produtividade deveriam ser positivamente correlacionadas, embora, na realidade, ocorra exatamente o contrário: produtividade e emprego tendem a ser, em geral, negativamente correlacionados (resultados não reportados na tabela). Este fato é conhecido como o "enigma da produtividade".

(c) Se choques tecnológicos equivalem ao principal fator gerador de flutuações econômicas, então a correlação entre medidas de produtividade e produto deveria ser alta. Entretanto, essa correlação costuma ser moderada na prática (ficando no intervalo de .4 a .6 para os Estados Unidos). Os resultados de Kydland e Prescott (1982), no entanto, apontam para uma correlação em torno de .9.

Os dois primeiros fatos são, em geral, tidos como os mais importantes, tendo dado origem a enigmas empíricos. Os desenvolvimentos ocorridos, 
relacionados ao mercado de trabalho em modelos RBC, concentraram-se, em sua maior parte, nesses enigmas.

Inspirado no enigma de variabilidade do emprego e no fato de que a maior parte das flutuações no fator trabalho, no caso da economia americana, deve-se a variações na quantidade de trabalhadores empregados ("margem extensiva"), em vez de variações nas horas ofertadas ("margem intensiva"), Hansen (1985) desenvolve um modelo RBC no qual introduz uma não-convexidade no conjunto de possibilidades de produção dos agentes, de modo que estes passam a ter a possibilidade de trabalhar em período integral ou de ficarem desempregados ("modelo de trabalho indivisível"). Para contornar o fato de o conjunto de possibilidades de consumo não ser convexo, o autor introduz a hipótese de que os agentes do modelo devem escolher loterias (em vez de horas trabalhadas), com os indivíduos na economia deparando-se com uma probabilidade de estarem empregados a cada período. A principal conclusão teórica advinda desse modelo diz respeito ao fato de ser possível obter uma elasticidade de substituição entre lazer e consumo ao longo de diferentes períodos que é infinita no caso do agente representativo da economia, embora os agentes individuais ainda exibam um valor relativamente baixo para essa elasticidade, um fato condizente com a evidência empírica.

Kydland e Prescott (1991a), por sua vez, consideram um modelo com variações em ambas as margens (intensiva e extensiva), chegando a um resultado no qual cerca de 70\% das flutuações ocorridas nos Estados Unidos ao longo do período 1954-1988 poderiam ser vistas como decorrentes de flutuações no resíduo de Solow, um valor ligeiramente menor do que aquele reportado originalmente por Prescott (1986a). ${ }^{24}$

Christiano e Eichenbaum (1992), partindo do enigma da produtividade e da controvérsia Dunlop-Tarshis, ${ }^{25}$ elaboram um modelo em que permitem, além da ocorrência de choques tecnológicos, choques nos gastos do governo (ou seja, choques de demanda agregada). No caso, esses choques atuariam no sentido de gerar deslocamentos da curva de oferta de trabalho que pudessem contrabalançar deslocamentos da curva de demanda por trabalho gerados a partir de choques tecnológicos. Com isto ocorrendo, haveria a possibilidade de o modelo obter uma menor correlação horas-produtividade, em acordo com a evidência empírica usual. O modelo desses 
autores, estimado a partir de uma versão modificada do método generalizado de momentos (General Method of Moments - GMM), tende a apresentar uma performance superior em relação a modelos RBC tradicionais, embora permaneça o enigma citado.

Hansen e Wright (1992), partindo dos enigmas citados, analisam os resultados decorrentes de um modelo RBC standard e de quatro extensões usuais na literatura (preferências não-separáveis, trabalho indivisível, choques nos gastos do governo e produção doméstica). Os resultados obtidos por esses últimos autores demonstram que as diferentes versões dos modelos considerados conseguem representar adequadamente algumas dimensões do mercado de trabalho norte-americano, embora nenhum modelo seja capaz de replicar a correlação horas-produtividade contida nos dados. Mais especificamente, algumas das diferentes extensões podem auxiliar na resolução do enigma da variabilidade do emprego, embora nenhuma delas seja capaz de resolver o enigma da produtividade.

\subsection{Críticas empíricas}

Tentativas pioneiras de verificação empírica de modelos RBC a partir do uso de técnicas econométricas convencionais equivalem aos trabalhos de Eichenbaum e Singleton (1986) e Altug (1989). No caso do primeiro trabalho, os autores buscam verificar a adequação empírica de modelos do gênero a partir de uma série de procedimentos envolvendo a estimação de modelos de vetores auto-regressivos (VARs) e a realização de testes de Granger-causalidade relacionando variáveis reais e nominais (especialmente medidas monetárias agregadas). Seus resultados demonstram a pouca importância de choques monetários sobre a volatilidade do produto americano no período pós-guerra. Ainda assim, os autores concluem que esta evidência não é, por si só, suficiente para fornecer uma base empírica sólida a modelos RBC. Altug, por sua vez, representa uma tentativa inovadora de verificação das propriedades empíricas desses modelos. No caso, a autora realiza estimações a partir do método de máxima-verossimilhança, procurando checar a adequação do modelo de Kydland e Prescott (1982). Seus resultados apontam para problemas relacionados ao fato de se considerar apenas um choque (tecnológico) nesse modelo, especialmente no tocante ao padrão da variável horas per capita. Ainda assim, a autora demonstra que a hipótese 
de preferências separáveis ao longo do tempo é consistente com seus resultados.

Hall (1988, 1990), utilizando dados desagregados da indústria norteamericana ao longo do período 1953-1984, desenvolve uma abordagem dual relacionada ao resíduo de Solow para checar a validade empírica de duas hipóteses básicas: (a) a igualdade entre preço e custo marginal, e (b) a ocorrência de retornos constantes de escala para essas indústrias. ${ }^{26} \mathrm{O}$ autor baseia sua análise na proposição denominada "propriedade de invariância do resíduo de Solow", que diz que

(...) Under competition and constant returns to scale, the Solow residual is uncorrelated with all variables known neither to be causes of productivity shifts nor to be caused by productivity shifts. (Hall, 1988: 924)

A partir daí, a lógica de seu teste é relativamente simples: basta verificar se as medidas do resíduo de Solow para os diversos grupos industriais que o autor considera não são correlacionadas com variáveis instrumentais previamente escolhidas. Ou seja, a hipótese de identificação do autor é que mudanças efetivas na produtividade não são correlacionadas com movimentos nas variáveis instrumentais consideradas, podendo-se, em última instância, testar conjuntamente as hipóteses de competição e retornos constantes de escala a partir do teste da hipótese de que a covariância do resíduo de Solow com o instrumento considerado seja nula. No caso, Hall $(1988,1990)$ considera três variáveis instrumentais: gastos militares, preços internacionais do petróleo e o partido político de presidentes americanos. Seus resultados apontam para a rejeição conjunta das hipóteses testadas, pelo fato de o resíduo de Solow mostrar-se correlacionado com as variáveis instrumentais consideradas. Na verdade, dada a lógica do teste empregado, caso o preço exceda o custo marginal na indústria, então o resíduo de Solow poderá exibir um padrão pró-cíclico mesmo que a tecnologia de produção subjacente permaneça inalterada, o que demonstra sua inadequação como proxy para choques tecnológicos em modelos RBC.

Apesar de esse estudo ter conseqüências diretas para a área de organização industrial (uma vez que implica que a indústria norte-americana pode ser caracterizada por um ambiente de concorrência imperfeita onde vigoram retornos crescentes de escala), sua implicação principal no caso presen- 
te diz respeito ao fato de que o resíduo de Solow não é uma medida plenamente exógena - conforme sugerido em nível teórico em alguns modelos $\mathrm{RBC}$ - , dada a sua correlação com as variáveis citadas.

Relacionado a essa última questão, há o estudo de Evans (1992), que procurou testar a precedência temporal de algumas variáveis macroeconômicas sobre o resíduo de Solow para os Estados Unidos ao longo do período 1957-1983. Usando dados trimestrais, o autor realiza testes de Granger-causalidade envolvendo uma medida de PTF e diversas variáveis macroeconômicas (conceito M1 de moeda, taxas de juros, índice de preços ao consumidor, gastos do governo e preços do petróleo). Para que a endogeneidade do resíduo de Solow seja comprovada, basta, segundo esse autor, que alguma das variáveis macroeconômicas citadas Granger-cause o resíduo de Solow. A partir de diferentes especificações, dois resultados básicos emergem: (a) o conceito de moeda empregado (M1), as taxas de juros e os gastos do governo Granger-causam a medida de PTF empregada no estudo; e (b) uma parte substancial dos impulsos relacionados à PTF (entre 25\% e 50\%) pode ser atribuída a variações de demanda agregada.

Por outro lado, interessados em estudar o fenômeno de retornos crescentes de curto prazo do fator trabalho (Short-Run Increasing Returns to Labor - SRIRL), Bernanke e Parkinson (1991) analisam uma amostra de dez indústrias manufatureiras americanas ao longo do período entre guerras. A intuição de seu teste é a seguinte: partindo do princípio de que a Grande Depressão americana não poderia ter sido causada por choques tecnológicos, os autores comparam a evolução de medidas industriais de produtividade ao longo desse período e no período pós-guerra. Se a abordagem RBC for, de fato, uma aproximação válida para o período pós-guerra, então seria de se esperar que o resíduo de Solow e o produto exibiriam movimentos na mesma direção apenas ao longo desse período, não sendo válido o mesmo raciocínio ao longo da Grande Depressão. Pela dificuldade de obtenção de dados para o primeiro período, os autores acabam utilizando uma medida de produtividade do trabalho como proxy para choques de produtividade. Seus resultados demonstram que as medidas de produto e de produtividade consideradas apresentam uma correlação maior ao longo da Grande Depressão do que no período pós-guerra, o que acaba colocando em dúvida a validade empírica de modelos RBC. 
Eichenbaum (1991) questiona a evidência empírica relacionada a modelos RBC baseada exclusivamente em resultados advindos do procedimento de calibração, colocando que essa evidência é extremamente frágil a ponto de ter alguma validade. Especificamente, o autor atenta para o elevado grau de incerteza amostral associado a parâmetros fundamentais de modelos do gênero (como o parâmetro $\rho$, por exemplo, que mede a persistência do choque tecnológico nesses modelos). Ao mesmo tempo, demonstra que um modelo RBC típico pode explicar algo entre 5\% e 200\% da variância do produto agregado, o que apenas confirma o alto grau de incerteza amostral associado a esses modelos. ${ }^{27}$

Baseando-se em técnicas de cointegração, King et al. (1991) testam a existência de uma tendência comum inerente às flutuações de diversas séries macroeconômicas americanas (produção, consumo e investimento). No caso, a confirmação da existência de uma tendência comum poderia ser vista como uma validação empírica de modelos RBC, uma vez que flutuações nesses modelos são geradas a partir de uma tendência estocástica comum advinda dos efeitos acumulados de choques de produtividade. Os resultados obtidos por esses autores tanto favorecem quanto refutam modelos RBC. Apesar de inicialmente detectarem a presença de uma tendência estocástica comum para as séries consideradas, o poder explicativo dessa hipótese é consideravelmente menor uma vez que variáveis adicionais (moeda, nível de preços e taxa de juros nominal) são incorporadas nos sistemas estimados.

Dadas as especulações de Summers (1986) e Mankiw (1989) a respeito da possibilidade de as estimativas do resíduo de Solow contidas em Prescott (1986a) serem afetadas pelo fenômeno de labor-hoarding, alguns autores desenvolveram abordagens alternativas, procurando verificar a validade empírica dessa possibilidade. Além de afetar medidas de produtividade, esse fenômeno pode ajudar a explicar o enigma da produtividade, uma vez que permite às firmas da economia ajustarem o fator trabalho efetivo sem necessariamente alterarem o nível de emprego, o que tende a reduzir a correlação entre a produtividade e o fator trabalho.

Shea (1992) elabora um teste criativo para verificar a ocorrência de labor-hoarding na indústria manufatureira norte-americana. Para tanto, o autor usa como proxy uma taxa de acidentes no trabalho. Sua hipótese de 
identificação, no caso, é a seguinte: como acidentes desse tipo só acontecem quando os indivíduos estão de fato trabalhando, é provável que aumentos na taxa de acidentes reflitam aumentos na intensidade de execução do trabalho. Assim, se o esforço-hora dos trabalhadores for pró-cíclico, é provável que o mesmo seja válido para a taxa de acidentes. Realizando estimações que controlam outros efeitos relacionados à jornada de trabalho (volume de horas extras e taxas de contratação/demissão de trabalhadores), o autor chega à conclusão de que o esforço dos trabalhadores nessa indústria é, de fato, pró-cíclico; uma evidência favorável à hipótese de labor-hoarding. Entretanto, um problema básico com o esquema de identificação adotado pelo autor diz respeito à possibilidade de a taxa de acidentes ser pró-cíclica, mesmo que o esforço seja acíclico, conforme é o caso de situações envolvendo horas extras, em que o cansaço dos trabalhadores pode aumentar o número reportado de acidentes sem que necessariamente ocorra um aumento na intensidade com que o trabalho é executado.

Burnside, Eichenbaum e Rebelo (1993) e Burnside e Eichenbaum (1996), por sua vez, checam a sensibilidade de medidas de PTF ao fenômeno de labor-hoarding e a variações na utilização da capacidade instalada, respectivamente. Ambos os artigos valem-se de uma versão modificada do método generalizado dos momentos (GMM).

No caso do primeiro artigo, os autores, partindo da hipótese de identificação de que inovações nos choques tecnológicos são independentes de inovações nos gastos do goveno, estimam a fração da variância do resíduo de Solow que se deve ao fenômeno de labor-hoarding. Os resultados obtidos demonstram que uma parcela considerável das flutuações no resíduo de Solow deve-se a comportamentos do tipo labor-hoarding, com modelos $\mathrm{RBC}$ superestimando o papel desempenhado por choques tecnológicos no curto prazo.

Em Burnside e Eichenbaum (1996), os autores investigam a importância, em termos quantitativos, de taxas de utilização da capacidade instalada (vistas aqui como uma forma de factor-hoarding) para modelos RBC. Seus resultados, além de demonstrarem a importância desse fator como mecanismo de propagação de choques nesses modelos, também demonstram que, no caso de taxas de utilização variáveis ao longo do tempo, a volatilidade de choques tecnológicos necessária para a geração de ciclos passa a ser 
consideravelmente inferior em comparação a modelos RBC standard (cerca de 33\% inferior). No caso, as taxas de utilização passam a ser variáveis endógenas do modelo, o que faz com que ocorram diferenças significativas entre o choque tecnológico efetivo (não observável) e o resíduo de Solow mensurado (observável). Ou seja, em ambas as ocasiões os autores concluem que modelos RBC usuais tendem a superestimar a proporção da variabilidade de choques tecnológicos responsável pela variabilidade do PNB norte-americano.

Em Burnside, Eichenbaum e Rebelo (1996), os autores exploram mais detalhadamente esse ponto, utilizando medidas corrigidas do resíduo de Solow - tanto em nível agregado quanto desagregado - a partir do uso da variável consumo industrial de energia elétrica como proxy para os serviços do capital. Esses autores obtêm resultados em que suas medidas corrigidas, além de apresentarem uma volatilidade consideravelmente menor do que medidas tradicionais (cerca de 70\% menor, no caso de dados trimestrais e anuais), também não são correlacionadas com a taxa de crescimento do produto, bem como passam a implicar menores probabilidades de regresso tecnológico (valores em torno de $10 \%$ no caso de dados trimestrais e $0 \%$ no caso de dados anuais). ${ }^{28}$ Esses resultados têm conseqüências diretas para modelos RBC, uma vez que choques de produtividade passam a apresentar uma volatilidade bem menor do que aquela suposta no caso dos modelos iniciais do gênero. Conseqüentemente, para que choques com uma variação tão pequena possam gerar ciclos nas magnitudes usualmente observadas, é preciso que existam fortes mecanismos de propagação dos choques tecnológicos iniciais sobre a economia.

Baseado em indicadores de gastos em P\&D e patentes, Shea (1998) realiza uma análise VAR em um painel contendo 19 indústrias manufatureiras ao longo do período 1959-1991. Seus resultados são os seguintes: choques tecnológicos positivos geram, no curto prazo, uma resposta positiva dos insumos de produção, embora esse padrão seja revertido no longo prazo. Adicionalmente, choques dessa natureza não afetam de maneira significativa as medidas de PTF consideradas pelo autor (qualquer que seja o horizonte considerado). Em termos gerais, choques tecnológicos tendem a explicar apenas uma pequena parcela da volatilidade dos insumos e da PTF no caso de horizontes equivalentes a ciclos de negócios. 
Partindo do enigma da produtividade, Galí (1999) procura demonstrar a inconsistência de algumas conclusões advindas de modelos RBC. Baseado em técnicas VAR, o autor consegue realizar uma decomposição dos choques incidentes sobre a economia em dois tipos: choques "tecnológicos" (ou de oferta, em termos gerais) e "não tecnológicos" (ou de demanda). Seus resultados básicos são os seguintes: (i) as correlações condicionais estimadas entre o fator trabalho e medidas de produtividade são negativas no caso de choques tecnológicos e positivas no caso de choques não tecnológicos; (ii) as funções impulso-resposta estimadas exibem um padrão de declínio persistente do fator trabalho em relação a choques tecnológicos positivos; e (iii) a produtividade exibe um padrão de crescimento temporário em relação a choques de demanda positivos. Esses três resultados representam uma forte evidência contra modelos RBC de primeira geração.

Outros autores obtiveram resultados semelhantes aos de Galí. Assim, Basu, Fernald e Kimball (1998), após construírem medidas corrigidas de PTF que levam em conta taxas variáveis de utilização dos fatores, bem como competição imperfeita e efeitos de agregação, obtêm um resultado em que os fatores de produção sofrem uma contração quando da ocorrência de um choque tecnológico, somente retornando ao nível de equilíbrio inicial após diversos anos. Segundo Galí (1999) e Basu, Fernald e Kimball (1998), uma resposta contracionista do fator trabalho a choques tecnológicos constituiria, por si só, uma forte evidência contra modelos RBC, ao mesmo tempo em que fortaleceria o poder explicativo de modelos baseados em preços rígidos.

Christiano, Eichenbaum e Vigfusson (2003) argumentam que os resultados obtidos por Galí devem-se a um erro de especificação básico cometido por esse autor quando da estimação do modelo VAR considerado, uma vez que medidas do fator trabalho podem ser representadas a partir de um processo estocástico estacionário. Logo, estimações que utilizem a variável horas em primeiras-diferenças estariam incorrendo em um problema de sobrediferenciação (overdifferencing). Sua conclusão básica é que, uma vez que seja levada em conta uma especificação mais condizente com o processo gerador de dados da variável horas, os resultados obtidos mudam drasticamente. Em particular, o fator trabalho passa a exibir uma resposta positiva a choques tecnológicos, o que vai de acordo com as previsões advindas de modelos RBC. Ainda assim, as demais conclusões obtidas por esses autores 
demonstram que choques tecnológicos têm uma importância pequena em freqüências cíclicas, com sua contribuição efetiva ocorrendo para longos horizontes de tempo, relacionados, em geral, a questões de crescimento econômico.

Francis e Ramey (2003) questionam os resultados de Christiano, Eichenbaum e Vigfusson (2003) a partir de diversos testes alternativos. Em particular, demonstram que o resultado principal obtido por Christiano, Eichenbaum e Vigfusson (em que o fator trabalho responde positivamente a choques tecnológicos) é obtido a um custo muito alto: VARs que levam em conta medidas de horas trabalhadas especificadas em níveis tendem a violar a condição de identificação básica desses modelos, nos quais choques não tecnológicos não exercem impactos de longo prazo sobre a medida de produtividade, por construção. Esse resultado tende a reforçar a evidência contida no estudo original de Galí. Adicionalmente, Francis e Ramey ressaltam

que a resposta contracionista do fator trabalho a choques tecnológicos não precisa ser vista necessariamente como uma evidência contrária a modelos RBC, uma vez que versões recentes desses modelos, que levam em conta certas hipóteses adicionais, também conseguem explicar esse padrão dinâmico (por exemplo, modelos com formação de hábito no consumo e custos de ajustamento no investimento). Embora esse debate levante diversas questões relevantes relacionadas aos principais resultados obtidos por Galí, ainda parece cedo para se obter algum padrão robusto a partir dos resultados (díspares) reportados nessa literatura. ${ }^{29}$

\section{APLICAÇÕES AO CASO BRASILEIRO}

Nos últimos anos, a pesquisa relacionada a ciclos de negócios no Brasil vem sendo caracterizada por valer-se cada vez mais da abordagem RBC, tanto no sentido de verificar os principais fatos estilizados dos ciclos de negócios quanto no de testar a adequação de modelos do gênero à economia brasileira. Os resultados obtidos, em geral, demonstram que a economia brasileira, além de ser nitidamente mais volátil do que a economia americana, não pode ser razoavelmente aproximada por um modelo RBC, mesmo quando são consideradas extensões do modelo básico, conforme é o caso de modelos com trabalho indivisível e restrições do tipo cash-in-advance, por exemplo. 
Kanczuk e Faria (2000) tentam verificar a adequação de um modelo RBC para a indústria brasileira. No caso, os autores consideram uma versão modificada do modelo de Hansen (1985), que contempla custos de ajustamento no investimento, usando dados industriais trimestrais provenientes do IBGE ao longo do período 1985:01-1999:03. Apesar de os resultados obtidos indicarem que a indústria brasileira apresenta um comportamento cíclico similar ao da economia americana, é enfatizada a sua maior volatilidade em relação à última, bem como a menor volatilidade relativa do investimento (em comparação ao produto) e a maior correlação consumo-renda que ocorre no caso brasileiro. Em termos gerais, os autores consideram os resultados obtidos como razoavelmente bons, demonstrando um certo otimismo em relação à aplicação de modelos de equilíbrio geral dinâmico ao contexto nacional. A limitação básica de seu trabalho diz respeito ao fato de estarem lidando com dados industriais, que tendem, em geral, a apresentar uma maior volatilidade em relação à economia como um todo. Ainda assim, esse estudo apresenta a vantagem de lidar com dados trimestrais, algo condizente com a prática usual na literatura de ciclos de negócios.

Val e Ferreira (2001), valendo-se de dados anuais ao testarem a adequação de diferentes modelos RBC ao contexto brasileiro, partem de uma estratégia alternativa: no caso, estimam parâmetros (via GMM) para serem usados em simulações, em vez de calibrá-los. Segundo os autores, a vantagem desse procedimento reside no fato de ser possível confrontar os valores estimados com valores calibrados, o que pode auxiliar em testes de robustez dos modelos em questão. Além de considerarem extensões com trabalho indivisível e restrições do tipo cash-in-advance, os autores também introduzem tributos nesse último modelo, procurando ver se ocorre alguma melhora significativa no ajuste do modelo em relação aos dados. Seus resultados reforçam alguns dos fatos usualmente reportados para a economia brasileira, como o fato de a série de consumo ser, em geral, consideravelmente mais volátil do que a série americana. Na verdade, do mesmo modo que no estudo de Kanczuk e Faria (2000), os autores constatam que todas as séries macroeconômicas consideradas em seu estudo são mais voláteis no caso do Brasil do que no dos Estados Unidos. Atentam ainda para problemas de mensuração das séries, especialmente no caso da série de consumo agregado. 
O trabalho de Ellery, Gomes e Sachsida (2002) representa um esforço pioneiro em termos agregados. Além de procurarem estabelecer fatos estilizados dos ciclos brasileiros nas últimas décadas, os autores, tentando contornar problemas de mensuração dos dados brasileiros, constroem uma detalhada base de dados própria para seu estudo e simulam modelos baseados em uma versão RBC standard e uma versão com trabalho indivisível. Dada a inexistência de dados agregados com periodicidade trimestral, os autores usam dados anuais para o período 1947-1998, embora acabem concentrando-se na análise de um período mais recente (1970-1998). A tabela 4 ilustra os principais resultados obtidos por esses autores, que consideram também o padrão cíclico da variável produtividade (do trabalho) em sua análise. ${ }^{30}$

Assim como no caso dos dados industriais analisados por Kanczuk e Faria (2000), é possível notar que a economia brasileira também é consideravelmente mais volátil do que a economia americana. A versão do modelo que inclui trabalho indivisível apresenta uma volatilidade do nível de renda superior à da economia real (cerca de 1,33 vez). A inclusão da variável produtividade, no caso, faz com que seja possível constatarmos a ocorrência de um dos problemas relacionados ao mercado de trabalho, conforme citado acima, qualquer que seja a versão considerada dos modelos simulados, uma vez que a correlação produtividade-renda para a economia brasileira é de aproximadamente 0,01 apenas, enquanto que para as economias com e sem trabalho indivisível é de cerca de 0,87 e 0,94, respectivamente. Em suma, os

Tabela 4: Resultados de Ellery, Gomes e Sachsida (2002) para a economia brasileira ao longo do período 1970-1998

\begin{tabular}{lcccccc}
\hline Variável & \multicolumn{2}{c}{ Economia brasileira } & \multicolumn{2}{c}{ Modelo standard } & \multicolumn{2}{c}{ Modelo trab. indivisível } \\
& $(\mathrm{a})$ & $(\mathrm{b})$ & $(\mathrm{a})$ & $(\mathrm{b})$ & $(\mathrm{a})$ & $(\mathrm{b})$ \\
\hline Produto & 5.48 & 1.00 & 5.33 & 1.00 & 7.28 & 1.00 \\
\hline Consumo & 5.17 & 0.77 & 2.89 & 0.85 & 4.61 & 0.86 \\
\hline Investimento & 12.55 & 0.85 & 13.21 & 0.95 & 17.32 & 0.93 \\
\hline Horas & 7.15 & 0.70 & 2.41 & 0.89 & 3.98 & 0.82 \\
\hline Produtividade & 5.11 & 0.01 & 3.37 & 0.94 & 4.62 & 0.87 \\
\hline
\end{tabular}

Fonte: Ellery, Gomes e Sachsida (2002: 303).

(1) Os dados usados para calcular as estatísticas acima possuem periodicidade anual, englobando o período 1970-1998. Todos os dados estão em escala logarítmica, tendo sido suavizados pelo filtro de Hodrick-Prescott.

(2) A coluna (a) corresponde aos valores dos desvios-padrão calculados para as variáveis consideradas, expressos em percentagem.

(3) A coluna (b) exibe a correlação de cada variável com o produto real.

(4) O termo horas serve para designar o total de horas trabalhadas na economia, representando o fator trabalho, no caso. 
resultados obtidos demonstram que os modelos considerados falham em replicar algumas das propriedades dos ciclos brasileiros, com os autores sugerindo que a pesquisa futura relacionada ao tema concentre-se em extensões e modelos alternativos capazes de explicar de maneira mais adequada o fenômeno em questão.

Alguns dos principais problemas empíricos com que se deparam os pesquisadores envolvidos com a agenda RBC no Brasil são os seguintes: primeiro, a forma de mensuração dos dados brasileiros nem sempre é feita de acordo com os princípios teóricos ideais de modelos RBC; segundo, a escolha dos parâmetros usados nas simulações de modelos desse tipo é feita, no caso de alguns parâmetros, de maneira arbitrária, dada a inexistência de estimativas específicas para o país.

No caso do primeiro problema há, por exemplo, dados relacionados às variáveis consumo e estoque de capital agregados. O caso do consumo já é relativamente bem documentado no país, tendo sido considerado na maior parte dos estudos recentes citados acima. No caso dessa série, há o problema de que o item "variação de estoques" - que, teoricamente, deveria ser incluído na série de investimento — vem sendo sistematicamente incluído na série de consumo desde 1986. Por outro lado, não existe para o país uma série de consumo de bens não duráveis que, teoricamente, deveria ser considerada como de consumo agregado de fato, devendo a série de consumo de bens duráveis ser considerada como investimento. Isto explicaria, por si só, o fato de a série brasileira de consumo agregado ser tão volátil. Como a série de consumo de bens duráveis é mais volátil do que a de não-duráveis — de acordo com os fatos estilizados dos ciclos de negócios - , é provável que isto acabe influenciando a volatilidade do consumo. Adicionalmente, há o problema de que no país a série de consumo agregado é calculada por resíduo, estando sujeita, conseqüentemente, a erros de mensuração. ${ }^{31}$

No caso do fator capital, há o problema de não existir para o país uma série oficial desse estoque. Ainda assim, autores brasileiros vêm contornando esse problema a partir da construção de séries de "serviços" do capital (baseando-se na hipótese de que o estoque de capital é diretamente proporcional a esses serviços), valendo-se, em geral, do "método de inventário perpétuo", que faz uso de séries de investimento para criar uma série de capital. ${ }^{32} \mathrm{Um}$ procedimento alternativo, relativamente comum na literatura nacional até alguns anos atrás, consiste no uso da proxy consumo não resi- 
dencial de energia elétrica para os serviços do capital. Entretanto, um problema relacionado ao uso dessa proxy diz respeito à possibilidade de a série de energia elétrica apresentar uma tendência, o que estaria refletindo, no caso, mudanças na composição do capital ou mudanças tecnológicas poupadoras de energia (Burnside, Eichenbaum e Rebelo, 1995: 73).

Em relação à escolha dos parâmetros em modelos RBC, fontes básicas para esses modelos equivalem a estudos com microdados e observações relacionadas ao crescimento de longo prazo. O problema básico, no caso brasileiro, diz respeito ao fato de não existirem no país muitos estudos que se valem de microdados (ou, pelo menos, não existe atualmente diversidade suficiente de estudos do gênero para validar a robustez dos parâmetros estimados), nem existem estudos que registrem, de forma sistemática, os fatos estilizados do crescimento para a economia brasileira. Conseqüentemente, os autores brasileiros envolvidos com a agenda de pesquisa RBC acabam tendo de recorrer ao seguinte procedimento: usar, para simulações envolvendo a economia brasileira, valores idênticos àqueles usados para a economia norte-americana, com esse procedimento sendo feito especialmente no caso de parâmetros tecnológicos.

Um problema, à primeira vista, decorrente dessa postura é que parece inadequado supor que parâmetros desse tipo sejam iguais em duas economias tão distintas quanto a brasileira e a americana. Considerar os mesmos parâmetros de calibração para essas duas economias - especialmente no que diz respeito a parâmetros relacionados ao choque tecnológico, a fonte básica de ciclos nesses modelos - equivale à suposição implícita de que existe um mesmo grau de desenvolvimento tecnológico entre economias distintas. Hansen (1997), por exemplo, demonstra que, dependendo da forma como o processo estocástico do choque tecnológico é modelado, podem ocorrer diferenças consideráveis em termos dos resultados obtidos a partir de um modelo RBC. A magnitude do viés decorrente desse tipo de prática é desconhecida até o momento, no entanto.

Em relação ao exposto acima, espera-se que a pesquisa nacional passe a se concentrar em fornecer respostas aos problemas citados. Adicionalmente, espera-se que, no futuro, ocorram tentativas de se testarem empiricamente modelos RBC a partir de técnicas econométricas convencionais, como forma de fornecer maior robustez aos resultados obtidos a partir de estudos baseados unicamente em exercícios de calibração. 


\section{CONCLUSÃO: UM CHOQUE TECNOLÓGICO POSITIVO?}

Em certa ocasião, Lucas chegou à conclusão de que os ganhos advindos de políticas anticíclicas seriam extremamente pequenos (Lucas, 1987: 27). Qual é a principal implicação desse resultado em termos de pesquisa macroeconômica? Basicamente, macroeconomistas deveriam ocupar-se mais do estudo de questões relacionadas ao longo prazo (crescimento econômico) do que de questões relacionadas ao curto prazo (ciclos).

Apesar de essa conclusão soar um tanto controversa (principalmente pela parametrização utilizada por Lucas em sua análise), é provável que o estudo dos ciclos de negócios ainda esteja longe de terminar (mesmo sendo menos importante - em termos de bem-estar social — do que o estudo do crescimento). Uma evidência favorável a isto é o aumento substancial da pesquisa relacionada a ciclos, tanto em nível teórico quanto empírico. E a maior parte dos desenvolvimentos recentes esteve ligada, de alguma forma, à agenda RBC. Por exemplo, a pesquisa recente vem incorporando diversas hipóteses adicionais aos modelos originais, como taxas variáveis de utilização dos fatores de produção, heterogeneidade dos agentes e choques tecnológicos específicos a certos setores da economia. Até mesmo elementos que à primeira vista poderiam ser tidos como incompatíveis com esses modelos, tais como moeda, contratos e preços rígidos, vêm sendo incorporados ultimamente (ver Cooley, 1995, a esse respeito).

Nos últimos vinte anos, os modelos RBC mostraram-se úteis não apenas no sentido de fornecer um maior rigor à análise macroeconômica, mas também por elucidarem diversas questões relacionadas às origens das flutuações econômicas. A principal contribuição dessa agenda de pesquisa parece ser de cunho eminentemente metodológico, conforme Danthine e Donaldson (1993) concluíram em uma resenha relacionada ao tema, escrita há mais de dez anos. De acordo com as tendências atuais, é provável que, no futuro, o novo core macroeconômico utilize o modelo RBC como workhorse básico, com a análise sendo enriquecida a partir da inclusão de hipóteses mais condizentes com os fatos reais, na linha das sugestões contidas em Goodfriend e King (1997), que falam do surgimento de uma Nova Síntese Neoclássica (NSN).

Desde seu início, a agenda RBC não teve a pretensão de apresentar uma única explicação para o fenômeno em estudo, mas, ao contrário, atentou 
para a necessidade de incorporação gradual de novas hipóteses aos modelos iniciais, como forma de explicar inconsistências teóricas e empíricas. Em particular, o caráter "autofágico" dessa agenda, no sentido ressaltado por Lisboa (1998a, b), fez com que ocorressem avanços substanciais em um período relativamente curto de tempo. A partir das conclusões controversas desses modelos, gerou-se todo um front de pesquisa teórica e empírica nos últimos vinte anos, o que pode levar à conclusão de que, em última instância, esses modelos representaram um choque tecnológico positivo para a macroeconomia como um todo.

\section{NOTAS}

1. Segundo Prescott (1991: 15), a denominação "RBC" pode ser atribuída a Long e Plosser (1983).

2. Sobre o debate novos-clássicos versus novos-keynesianos, ver Magalhães (2000) e as referências lá contidas.

3. Para uma descrição detalhada das contribuições desses autores que acabaram levando à premiação por parte do Comitê do Nobel, ver Kydland (2004).

4. Essa preocupação já estava presente na obra de Schumpeter, com esse autor argumentando que inovações tecnológicas poderiam, simultaneamente, gerar ciclos e crescimento de longo prazo (Cooley e Prescott, 1995: 2).

5. Este fato estilizado fora inicialmente reportado em Kydland e Prescott (1990), tendo gerado certa controvérsia na época de sua divulgação. Ver maiores detalhes a esse respeito adiante.

6. Essa tabela equivale a uma adaptação de tabelas contidas em Cooley e Prescott (1995: 30-31) (fatores reais) e Cooley e Hansen (1995: 180-181) (fatores monetários). Ver ainda Stock e Watson (2000), para uma descrição mais detalhada dos fatos estilizados dos ciclos de negócios na economia americana.

7. Sobre algumas das contribuições substanciais de Lucas relacionadas a ciclos de negócios, ver seus artigos originais (Lucas, 1972, 1973, 1975, 1977). Lucas (1981) representa uma coletânea contendo esses e outros artigos. Opiniões posteriores desse autor sobre o tema estão contidas em Lucas (1987, 1996, 2003). Uma resenha parcial e didática da obra desse autor está contida em Chari (1998). Ver ainda Sargent (1996), que ressalta a importância das principais contribuições de Lucas para a pesquisa macroeconômica contemporânea.

8. Um reflexo direto dessas recomendações está contido em Prescott (1998), por exemplo, que enumera alguns princípios básicos relacionados à pesquisa em ciclos de negócios.

9. Hoje em dia, existe uma ampla variedade de resenhas relacionadas à agenda de pesquisa RBC, cujo grau de profundidade varia de acordo com os objetivos de cada autor. Extensas resenhas críticas estão contidas em McCallum (1989), Stadler (1994), Cooley e Pres- 
cott (1995) e King e Rebelo (2000). No caso de exposições didáticas, ver Plosser (1989), Prescott (1991), Hansen (1994), Romer (1996, cap. 4) e Kydland (2004). Um volume contendo diversas contribuições realizadas até meados da década de 1990 equivale a Cooley (1995). Rebelo (2005) trata de algumas perspectivas futuras relacionadas a essa agenda de pesquisa. Uma extensa lista de referências relacionadas a essa área está contida em Zimmermann (1996).

10. Lisboa (1998a: 51-54) trata desse erro semântico ocorrido na literatura econômica. A breve exposição do conceito que se segue é baseada em Chari (1998).

11. A exposição descrita adiante é baseada em Kydland (2004), sendo deliberadamente simplificada e parcial, uma vez que a intenção aqui é apenas ressaltar algumas das principais hipóteses relacionadas a modelos RBC de primeira geração como forma de facilitar a descrição das contribuições citadas ao longo do texto.

12. Daí o nome desse artigo, "Time to Build and Aggregate Fluctuations", uma vez que leva um certo tempo para a constituição plena do estoque de capital dessa economia.

13. Intuitivamente, essa última hipótese faz com que o fator trabalho sofra uma espécie de "efeito-fadiga": quanto mais alguém trabalhou no passado, mais valoriza o tempo dedicado ao lazer atualmente. Esta hipótese acaba aumentando o grau de substituição intertemporal de lazer do agente no modelo.

14. O filtro Hodrick-Prescott (H-P) equivale a um filtro linear usado para a extração do componente de longo prazo de uma série. A partir da subtração desse componente da série original, é possível para o pesquisador obter o componente "cíclico" da série. Dada a sua enorme popularidade em macroeconomia nas duas últimas décadas (o filtro foi criado originalmente em 1980), não nos deteremos em explicações detalhadas a esse respeito. Para maiores informações, ver Hodrick e Prescott (1997).

15. Sobre métodos de resolução de modelos RBC, ver Hansen e Prescott (1995). Uma breve introdução a técnicas de programação dinâmica está contida em Sargent e Ljungqvist (2000, cap. 2). Para uma contextualização histórica dos avanços relacionados ao procedimento de calibração, ver Kydland e Prescott (1991b). No caso de uma descrição mais exaustiva e didática das definições e etapas relacionadas a esse procedimento, ver Kydland e Prescott (1996). Para uma visão crítica a esse respeito, ver, a título de exemplo, Hansen e Heckman (1996).

16. Uma alternativa ao último procedimento citado equivale à escolha de um valor para a variância do choque de produtividade que esteja de acordo com as características de uma medida de produtividade da economia real. Entretanto, em termos práticos, este revela-se como um procedimento bastante frágil, dadas as dificuldades relacionadas ao cálculo de medidas de produtividade (ver adiante).

17. O termo steady-state (ou "estado estacionário") serve para designar a situação em que as variáveis do modelo crescem a taxas constantes (Barro e Sala-i-Martin, 1995: 19).

18. Historicamente, a abordagem de Kydland-Prescott prevalesceu sobre a de Long-Plosser, sendo amplamente empregada nas pesquisas de ciclos de negócios da atualidade.

19. De fato, o resíduo mede a variação do produto que não pode ser explicada pela variação nas quantidades de capital e trabalho, sendo, em última instância, uma "medida da nos- 
sa ignorância", conforme citado originalmente por Moses Abramovitz, em 1956 (Griliches, 1994: 5). Sobre a evolução histórica desse conceito, ver Griliches (1996) e Hulten (2000).

20. Outra evidência empírica divulgada no início da década de 1980 e que também serviu para ressaltar a importância de fatores reais (em detrimento de fatores nominais) como fonte de flutuações econômicas foi o estudo clássico de Nelson e Plosser (1982), relacionado à aplicação de testes de raiz unitária sobre diversas séries macroeconômicas americanas.

21. Outros resultados controversos relacionados a modelos RBC equivalem à "causação reversa” da relação moeda-renda (King e Plosser, 1984) e ao padrão contracíclico do nível de preços ao longo do período pós-guerra (Kydland e Prescott, 1990). O último resultado, em particular, já vem sendo confirmado por outros estudos empíricos há algum tempo (ver Backus e Kehoe, 1992, Basu e Taylor, 1999, e Stock e Watson, 2000, por exemplo). Não nos deteremos em descrever detalhadamente esses resultados, dada a presente ênfase na importância de fatores reais como mecanismos geradores de flutuações econômicas. Leitores interessados devem consultar, além das referências originais, Cooley e Hansen (1995).

22. Sobre o debate Prescott-Summers, ver, além de Prescott (1986a, b) e Summers (1986), Manuelli (1986).

23. Em termos da expressão do resíduo de Solow descrita acima, isso pode ser visto como um aumento em $\Delta y$ sem um aumento correspondente em $\Delta n$, o que pode levar à conclusão errônea de que houve um aumento na produtividade (medida via resíduo de Solow). Uma outra possibilidade de viés no resíduo de Solow seria oriunda de variações nas taxas de utilização dos fatores de produção (maiores detalhes adiante).

24. Outros modelos RBC chegam a permitir taxas de utilização do fator capital variáveis ao longo do tempo, conforme atestam os trabalhos de Greenwood, Hercowitz e Huffmann (1988), Kydland e Prescott (1988) e Bils e Cho (1994), por exemplo.

25. Esta controvérsia, levantada originalmente por John T. Dunlop e Lorie Tarshis de forma independente no final da década de 1930, equivale ao resultado empírico onde as variáveis salário real e emprego não são inversamente correlacionadas, ao contrário das principais implicações advindas dos modelos Clássico e Keynesiano de livros-texto de Macroeconomia (ver, por exemplo, Sargent 1987, cap. 1 e 2).

26. Vale lembrar que essas duas hipóteses são fundamentais à derivação de Solow (1957).

27 Aiyagari (1994) também questiona a contribuição de choques tecnológicos em modelos RBC, embora proponha uma metodologia alternativa de cálculo para essa contribuição, obtendo valores superiores àqueles reportados originalmente por Prescott (1986a).

28. Segundo os autores, a probabilidade de regresso tecnológico pode ser definida como a proporção de vezes na amostra em que o nível estimado de tecnologia (taxas de crescimento de medidas de PTF, ou seja, o resíduo de Solow) declinou (Burnside, Eichenbaum e Rebelo, 1996).

29. Um resumo desse debate empírico está contido em Galí e Rabanal (2004). 
30. Um procedimento padrão na literatura RBC é considerar a variável produtividade do trabalho quando da verificação dos fatos estilizados da economia real em questão, embora a fonte de choques nesses modelos seja originada a partir de taxas de variação da produtividade total dos fatores (PTF), ou seja, do resíduo de Solow.

31. Ellery, Gomes e Sachsida (2002) tentam contornar esses problemas construindo séries distintas de consumo de bens duráveis e não duráveis para o Brasil ao longo do período 1970-1998.

32. Na verdade, este é um problema comum na literatura sobre o tema. Ver, a esse respeito, Griliches (1994), Hulten (2000) e o próprio estudo original de Solow (1957).

\section{REFERÊNCIAS BIBLIOGRÁFICAS}

AIYAGARI, S. R. (1994) "On the contribution of technology shocks to business cycles". Federal Reserve Bank of Minneapolis Quarterly Review, v. 18, n. 1, p. 22-34, Winter.

ALTUG, S. (1989) “Time-to-build and aggregate fluctuations: some new evidence”. International Economic Review, v. 30, n. 4, p. 889-920.

BACKUS, D. K., KEHOE, P. J. (1992) "International evidence on the historical properties of business cycles”. American Economic Review, v. 82, n. 4, p. 864-888.

BARBOSA, E. S. (1992) “Uma exposição introdutória da macroeconomia novo-clássica”. In: M. L. Silva (ed.), Moeda e produção: teorias comparadas. Brasília: UnB, p. 233-281.

BARRO, R. J., SALA-I-MARTIN, X. (1995) Growth Economics. Nova York: McGraw-Hill, 450 p.

BASU, S., FERNALD, J. G., KIMBALL, M. (1998) Are technology improvements contractionary? Board of Governors of the Federal Reserve System, International Finance Discussion Paper Series n. 625, Sept., 56 p.

, TAYLOR, A. M. (1999) "Business cycles in international historical perspective". Journal of Economic Perspectives, v. 13, n. 2, p. 45-68.

BERNANKE, B. S., PARKINSON, M, L. (1991) "Procyclical labor productivity and competing theories of the business cycle: some evidence from interwar U.S. manufacturing industries". Journal of Political Economy, v. 99, n. 3, p. 439-459.

BILS, M., CHO, J.-O. (1994) “Cyclical factor utilization”. Journal of Monetary Economics, v. 33, n. 3, p. 319-354.

BURNSIDE, C., EICHENBAUM, M. (1996) "Factor-hoarding and the propagation of businesscycle shocks". American Economic Review, v. 86, n. 5, p. 1.154-1.174.

, REBELO, S. (1993) "Labor hoarding and the business cycle". Journal of Political Economy, v. 101, n. 2, p. 245-273.

— — - (1995) "Capital utilization and returns to scale". NBER Macroeconomics Annual, p. 67-110.

(1996) "Sectoral Solow residuals". European Economic Review, v. 40, n. 4, p. 861-869, Apr.

CARD, D. (1991) Intertemporal labor supply: an assessment. NBER Working Paper n. 3602, Jan., 47 p. 
CHARI, V. V. (1998) "Nobel Laureate Robert E. Lucas, Jr.: architect of modern macroeconomics". Journal of Economic Perspectives, v. 12, n. 1, p. 171-186, Winter.

CHRISTIANO, L. J., EICHENBAUM, M. (1992) "Current Real-Business-Cycle theories and aggregate labor market fluctuations”. American Economic Review, v. 82, n. 3, p. 430-450.

— - VIGFUSSON, R. (2003) What happens after a technology shock? Northwestern University, mimeo., May, $52 \mathrm{p}$.

COOLEY, THOMAS F. (ed.) (1995) Frontiers of business cycle research. Nova Jersey: Princeton University, $420 \mathrm{p}$.

— - HANSEN, G. D. (1995) "Money and the business cycle”. In: T. F. Cooley (ed.), Frontiers of business cycle research. Nova Jersey: Princeton University, p. 179-216.

— PRESCOTT, E. C. (1995) "Economic growth and business cycles". In: T. F. Cooley (ed.), Frontiers of business cycle research. Nova Jersey: Princeton University, p. 1-38.

DANTHINE, J.-P., DONALDSON, J. B. (1993) "Methodological and empirical issues in real business cycle theory". European Economic Review, v. 37, n. 1, p. 1-35.

EICHENBAUM, M. (1991) "Real business-cycle theory: wisdom or whimsy?". Journal of Economic Dynamics and Control, v. 15, n. 4, p. 607-626.

-, SINGLETON, K. J. (1986) "Do equilibrium real business cycle theories explain postwar U.S. business cycles?” In: S. Fischer (ed.), NBER Macroeconomics Annual, p. 91134, p. 63-130.

ELLERY, R. G., JR., GOMES, V., SACHSIDA, A. (2002) "Business cycle fluctuations in Brazil”. Revista Brasileira de Economia, v. 56, n. 2, p. 269-308, abr.-jun.

EVANS, C. I. (1992) "Productivity shocks and real business cycles". Journal of Monetary Economics, v. 29, n. 2, p. 191-208, Apr.

FAY, J. A., MEDOFF, J. L. (1985) "Labor and output over the business cycle: some direct evidence". American Economic Review, v. 75, n. 3, p. 638-655, Sept.

FRANCIS, N., RAMEY, V. A. (2003) Is the technology-driven real business cycle hypothesis dead? Shocks and aggregate fluctuations revisited. UCSD Working Paper, Sept., 37 p.

GALÍ, J. (1999) "Technology, employment and the business cycle: do technology shocks explain aggregate fluctuations?” American Economic Review, v. 89, n. 1, p. 249-271, Mar.

— RABANAL, P. (2004) “Technology shocks and aggregate fluctuations: how well does the RBC model fit postwar U.S. data?". NBER Macroeconomics Annual.

GOODFRIEND, M., KING, R. G. (1997) "The new neoclassical synthesis and the role of monetary policy”. In: B. S. Bernanke e J. J. Rotemberg (eds.), NBER macroeconomics annual. Cambridge: MIT, p. 231-283.

GREENWOOD, J., HERCOWITZ, Z., HUFFMAN, G. W. (1988) "Investment, capacity utilization and the real business cycle". American Economic Review, v. 78, n. 3, p. 402-417, Jun.

GRILICHES, Z. (1994) The residual, past and present: a personal view. Cambridge: Harvard University, mimeo., $37 \mathrm{p}$.

_ (1996) "The discovery of the residual: a historical note". Journal of Economic Literature, v. 34, n. 1, p. 1.324-1.330, Sept. 
HALL, R. E. (1988) “The relation between price and marginal cost in U.S. industry". Journal of Political Economy, v. 96, n. 5, p. 921-947.

(1990) "Invariance properties of Solow's productivity residual". In: P. Diamond (ed.), Growth/Productivity/Unemployment: essays in honour of Bob Solow's 70 th birthday. Cambridge: MIT, p. 71-112.

HANSEN, G. D. (1985) "Indivisible labor and the business cycle". Journal of Monetary Economics, v. 16, n. 3, p. 309-327.

- (1994) "What is real business cycle theory?". Jobs and Capital (Milken Institute for Job and Capital Formation), v. 3, p. 7-10.

- (1997) “Technical progress and aggregate fluctuations". Journal of Economic Dynamics and Control, v. 21, n. 4, p. 1.005-1.023.

— PRESCOTT, E. C. (1995) "Recursive methods for computing equilibria of business cycle models”. In: T. F. Cooley (ed.), Frontiers of business cycle research. Nova Jersey: Princeton University, p. 39-64.

—, WRIGHT, R. (1992) “The labor market in real business cycle theory". Federal Reserve Bank of Minneapolis Quarterly Review, p. 2-12, Spring.

HANSEN, L. P., HECKMAN, J. (1996) “The empirical foundations of calibration”. Journal of Economic Perspectives, v. 10, n. 1, p. 87-104.

HODRICK, R., PRESCOTT, E. C. (1997) “Post-War U.S. business cycles: a descriptive empirical investigation". Journal of Money, Credit and Banking, v. 29, n. 1, p. 1-16.

HULTEN, C. R. (2000) Total factor productivity: a short biography. NBER Working Paper n. 7.471, Jan., 75 p.

LUCAS, R. E. JR. (1996) “Nobel lecture: monetary neutrality”. Journal of Political Economy, v. 104, n. 4 , p. 661-682.

KANCZUK, F., FARIA, F., JR. (2000) “Ciclos reais para a indústria brasileira?”. Estudos Econômicos, v. 47, n. 4, p. 335-350.

KING, R. G., PLOSSER, C. I. (1984) "Money, credit and prices in a real business cycle". American Economic Review, v. 74, n. 3, p. 363-380.

STOCK, J. H., WATSON, M. W. (1991) "Stochastic trends and economic fluctuations". American Economic Review, v. 81, n. 4, p. 819-940.

— REBELO, S. (2000) "Ressuscitating real business cycles". In: J. Taylor e M. Woodford (eds.), Handbook of Macroeconomics. North-Holland, p. 927-1.007.

KYDLAND, F. (2004) "Nobel lecture: quantitative aggregate theory”. Federal Reserve Bank of Dallas, $10 \mathrm{p}$.

, PRESCOTT, E. C. (1982) “Time to build and aggregate fluctuations”. Econometrica, v. 50, n. 6 , p. $1.345-1.370$.

(1988) "The workweek of capital and its cyclical implications". Journal of Monetary Economics, v. 21, n. 3, p. 343-360.

(1990) "Business cycles: real facts and a monetary myth". Federal Reserve Bank of Minneapolis Quarterly Review, v. 14, n. 2, p. 3-18. 
(1991 [1991a]) "Hours and employment variation in business cycle theory". Economic Theory, v. 1, n. 1, p. 63-81.

(1991 [1991b]) "The econometrics of the general equilibrium approach to business cycles". Scandinavian Journal of Economics, v. 93, n. 2, p. 161-178.

(1996) “The computational experiment: an econometric tool”. Journal of Economic Perspectives, v. 10, n. 1, p. 69-85.

LISBOA, M. (1998 [1998a]) "A miséria da crítica heterodoxa. Primeira parte: sobre as críticas”. Revista de Economia Contemporânea, v. 2, n. 1, p. 5-66.

(1998 [1998b]) “A miséria da crítica heterodoxa. Segunda parte: método e equilíbrio na tradição neoclássica”. Revista de Economia Contemporânea, v. 2, n. 2, p. 113-151.

LONG, J. B., PLOSSER, C. I. (1983) "Real business cycles”. Journal of Political Economy, v. 9, n. 1, p. 39-69.

LUCAS, R. E. JR. (1972) "Expectations and the neutrality of money". Journal of Economic Theory, v. 4, n. 2, p. 103-124.

- (1973) "Some international evidence on output-inflation tradeoffs". American Economic Review, v. 63, n. 3, p. 326-334.

- (1975) “An equilibrium model of the business cycle”. Journal of Political Economy, v. 83 , n. 6, p. 1.113-1.144.

(1976) "Econometric policy evaluation: a critique". Carnegie-Rochester Conference Series on Public Policy, v. 1, p. 19-46.

(1977) "Understanding business cycles". In: K. Brunner e A. Meltzer (eds.), Stabilization of the domestic and international economy. Amsterdam: North-Holland Publishing Company, v. 5, p. 7-29.

- (1980) "Methods and problems in business cycle theory". Journal of Money, Credit and Banking , v. 12, n. 4, p. 696-715.

- (1981) Studies in business-cycle theory. Cambridge: MIT Press.

(1987) Models of business cycles (Yrjö Jahnsson Lectures). Basil and Blackwell.

(2003) “Macroeconomic priorities". American Economic Review, v. 93, n. 1, p. 1-14, Mar.

MAGAlHÃES, M. A. (2000) “Explicando os ciclos de negócios”. Economia Aplicada, v. 4, n. 1, p. 157-189, jan.-mar.

MANKIW, N.G. (1989) "Real business cycles: a new keynesian perspective". Journal of Economic Perspectives, v. 3, n. 3, p. 79-90, Summer.

MANUELLI, R. E. (1986) "Modern business cycle analysis: a guide to the Prescott-Summers debate”. Federal Reserve Bank of Minneapolis Quarterly Review, v. 10, n. 4, p. 3-8, Fall.

McCALluM, B. T. (1989) "Real business cycle models". In: R. Barro (ed.), Handbook of modern business cycle theory. Oxford: Basil Blackwell, p. 16-50.

NELSON, C. R., PLOSSER, C. I. (1982) “Trends and random walks in macroeconomic time series: some evidence and implications". Journal of Monetary Economics, v. 10, n. 2, p. 139-162. 
OI, W. Y. (1962) "Labor as a quasi-fixed factor". Journal of Political Economy, v. 70, n. 5, p. 538-555, Dec.

PLOSSER, C. I. (1989) "Understanding real business cycles". Journal of Economic Perspectives, v. 3, n. 3, p. 51-77.

PRESCOTT, E. C. (1986 [1986a]) “Theory ahead of business cycle measurement”. Federal Reserve Bank of Minneapolis Quarterly Review, v. 10, n. 4, p. 9-22, Fall.

- (1986 [1986b]) “Response to a skeptic". Federal Reserve Bank of Minneapolis Quarterly Review, v. 10, n. 4, p. 28-33, Fall.

- (1991) "Real business cycle theory: what have we learned?" Revista de Análisis Económico, v. 6, n. 2, p. 3-19.

_ (1998) Business cycle research: methods and problems. Federal Reserve Bank of Minneapolis Research Department Working Paper n. 590, Oct., 28 p.

REBELO, S. (2005) Real Business Cycle models: past, present and future. Northwestern University, mimeo., Mar., $25 \mathrm{p}$.

ROMER, D. H. (1996) Advanced macroeconomics. Nova York: McGraw-Hill.

SARGENT, T. J. (1987) Macroeconomic Theory. San Diego: Academic Press.

(1996) "Expectations and the nonneutrality of Lucas". Journal of Monetary Economics, v. 37, n. 4, p. 535-548.

—, LJUNGQVIST, L. (2000) Recursive Macroeconomic Theory. Cambridge: MIT Press.

SHEA, J. (1992) Accident rates, labor effort, and the business cycle. University of Winsconsin at Madison, mimeo., Mar., $32 \mathrm{p}$.

- (1998) "What do technology shocks do?". NBER Macroeconomics Annual.

SOLOW, R. M. (1956) “A contribution to the theory of economic growth”. Quarterly Journal of Economics, v. 70, n. 1, p. 65-94, Feb.

- (1957) "Technical change and the aggregate production function". The Review of Economics and Statistics, v. 39, n. 3, p. 312-320, Aug.

STADLER, G. W. (1994) “Real business cycles". Journal of Economic Literature, v. 32, n. 4, p. 1.750-1.783, Dec.

STOCK, J. H., WATSON, M. W. (2000) "Business cycle fluctuations in U.S. macroeconomic time series”. In: J. Taylor e M. Woodford (eds.), Handbook of Macroeconomics, NorthHolland, p. 3-64.

SUMMERS, L. H. (1986) “Some skeptical observations on real business cycle theory”. Federal Reserve Bank of Minneapolis Quarterly Review, v. 10, n. 4, p. 23-27, Fall.

VAL, P. R. C., FERREIRA, P. C. G. (2001) "Modelos de ciclos reais de negócios aplicados à economia brasileira”. Pesquisa e Planejamento Econômico, v. 31, n. 2, p. 213-248, ago.

ZIMMERMANN, C. (1996) A Real Business Cycle bibliography. CREFE Working Paper n. 43, Jul., 55 p. 